\title{
Reconstruyendo el conocimiento práctico en confinamiento. Una experiencia de enseñanza en la formación inicial de docentes
}

\section{Rebuilding practical knowledge in confinement. A teaching experience in Initial Teacher Training}

\author{
Encarnación Soto Gómez \\ Universidad de Málaga. Málaga, España \\ esoto@uma.es \\ Gonzalo Maldonado-Ruiz \\ Universidad de Málaga. Málaga, España \\ gonzamaldo@uma.es \\ Ana Márquez-Román \\ Universidad de Málaga. Málaga, España \\ marquezr@uma.es \\ Noemí Peña Trapero \\ Universidad de Málaga. Málaga, España \\ noemiptr@uma.es
}

\begin{abstract}
Resumen
Este artículo presenta la experiencia y los dilemas de enseñanza de un grupo de docentes en la formación inicial de profesorado del Grado en Educación Infantil, en su adaptación a la virtualidad ocasionada por la COVID-19. Un proyecto que, con 10 años de andadura, ofrece una oportunidad para repensar la formación inicial en el marco del confinamiento. Inicialmente se describe el complejo e incierto contexto social actual y los retos ineludibles para la formación inicial del profesorado: la reconstrucción del conocimiento práctico de nuestras estudiantes y el diseño de un habitus vivencial y crítico como sostén de los principios pedagógicos de la experiencia que describimos en la segunda parte. Un triángulo didáctico en relación permanente con las reflexiones de las estudiantes y los debates e inquietudes que como docentes hemos compartido en los espacios de coordinación y adaptación a la virtualidad. Las conclusiones de esta experiencia sitúan la coordinación y la tutorización como ejes relevantes, al mismo tiempo en el que se advierten las dificultades e imposibilidad de que una experiencia de formación inicial de docentes íntegramente virtual -sin una práctica en relación y presencia de los niños y niñas- facilite la reconstrucción del conocimiento práctico de maestras y maestros de Educación Infantil.
\end{abstract}

Palabras clave: formación inicial del profesorado, conocimiento práctico, educación a distancia, tutorización, coordinación docente

\begin{abstract}
This article presents the experience and teaching dilemmas of a group of teachers in the Initial Early Childhood Teachers' Training, in their adaptation to the virtuality caused by COVID-19. A 10-year-old project that offers an opportunity to rethink Initial Teacher Training in confinement. Initially, the complex and uncertain current social context and the inescapable challenges for Initial Teacher Training are described: the reconstruction of the practical knowledge of our students and the design of an experiential and critical habitus as support for the pedagogical principles of the experience that we describe in the second part. A didactic triangle in permanent relationship with the students' reflections and the debates and concerns that we, as teachers, have shared in the spaces of coordination and adaptation to virtuality. The conclusions of this experience place coordination and tutoring as relevant axes. At the same time, the difficulties and impossibility of a fully virtual Initial Teacher Training experience facilitating the reconstruction of the practical knowledge of Early Childhood Education teachers without a practice in relation to children are noted.
\end{abstract}

Keywords: initial teacher training, practical knowledge, e-learning, mentoring, teaching coordination 


\section{Introducción}

Este es el relato de una experiencia docente en el marco de la formación inicial del profesorado de Educación Infantil y su adaptación a la virtualidad ocasionada por la COVID-19.

Una reflexión sobre un proceso de innovación docente en tiempos de confinamiento con el que esperamos contribuir, a partir de nuestra experiencia investigadora y docente, al debate sobre la necesaria relación entre la teoría y la práctica en la formación inicial del profesorado.

En la primera parte y como contenido del marco teórico de la experiencia, iniciamos el debate abordando la compleja e incierta realidad que caracteriza el escenario social y natural en el que vivimos. Un contexto local co-implicado globalmente. Un conjunto de interrelaciones y flujos que pone de manifiesto el carácter sistémico de todos los fenómenos y procesos humanos.

Una red de variables complejamente interrelacionadas que necesitamos comprender con urgencia, para definir los retos ineludibles de la formación inicial de docentes. Retos que requieren con urgencia, el diseño de un habitus pedagógico menos transmisivo y más vivencial donde se pongan en juego dos movimientos claves para facilitar la reconstrucción del confuso y anacrónico conocimiento práctico con el que nuestras estudiantes inician su formación como maestras y maestros: la experimentación de la teoría y la teorización de la práctica. Un marco teórico compartido y contrastado con diferentes autores que nos ayudan a definir los principios pedagógicos que sostienen la experiencia que aquí presentamos.

En la segunda parte, y de forma más concreta, presentamos tanto el sentido, el modelo y los procedimientos de enseñanza y aprendizaje de la experiencia, como los sucesivos dilemas dificultades y retos a los que nos hemos enfrentado tras el estado de alarma decretado por el Gobierno español el 14 de marzo de 2020 por el coronavirus COVID19. Un proyecto que, a pesar de contar con 10 años de experiencia presencial, ha supuesto un nuevo desafío y oportunidad de revisión de nuestro proyecto.

Como ejes de análisis de nuestra experiencia, ponemos sobre la mesa tres voces fundamentales: los principios y estrategias pedagógicas que vertebran nuestra práctica como docentes; las evidencias obtenidas por parte de las estudiantes participantes (la mayoría de ellas, chicas) recogidas en sus diarios de aprendizaje de su Portafolios Virtual; y nuestras propias inquietudes y reflexiones, recogidas en las diferentes plataformas de coordinación utilizadas.

En este sentido, todas las evidencias recogidas a lo largo de la descripción y análisis de la experiencia (extraídas de los momentos de encuentro con las estudiantes, las diferentes tareas propuestas y nuestras propias conversaciones entre docentes vía chat) se presentan como hitos emergentes y sintomáticos que en ningún caso constituyen reflexiones anecdóticas y aisladas, sino que recogen lugares comunes o ejes de convergencia de la experiencia que nos ayudan a repensar lo vivido.

Como síntesis del cuerpo de reflexiones y aprendizajes derivados de la experiencia, podríamos destacar la importancia y dificultad de repensar organizativa y didácticamente cada uno de los componentes del proyecto didáctico sin trasladar mecánicamente el proyecto didáctico de lo presencial a lo virtual. Esto requiere el cuidando de las emociones derivadas del proceso de confinamiento a través de una tutoría cercana y una

Reconstruyendo el conocimiento práctico en confinamiento. Una experiencia de enseñanza en la formación inicial de docentes. Soto, Maldonado-Ruiz, Márquez-Román \& Peña. 
reorganización y revisión profunda de los tiempos, recursos y estrategias y plataformas digitales de enseñanza y aprendizaje.

En definitiva y como veremos a lo largo del artículo, esta experiencia muestra nuestra propia transformación y adaptación a la enseñanza virtual en el intento de construir un habitus pedagógico flexible y estimulante como valor clave para movilizar el conocimiento práctico de las estudiantes, aunque no suficiente para reconstruirlo o desarrollar competencias fundamentales, ya que una experiencia de formación inicial de docentes $100 \%$ online difícilmente recrea un contexto situado de una práctica en relación y presencia con los niños y niñas.

\section{Marco contextual}

La pandemia del COVID-19 se ha convertido, desde la Educación Infantil hasta la universidad, en una cuestión por resolver para el ya complejo sistema educativo español. La escuela ha venido resistiendo, con sus inercias académicas, las transformaciones de una era global y digitalizada saturada de intercambios simbólicos y cambiantes, generadores de contrastes y desigualdades (Morin, 2001; Bauman y Leoncini, 2018). Un crisol de políticas, identidades, intereses y tendencias económicas que dificulta el desarrollo de un ser humano cognitiva y emocionalmente capaz de vivir con cierta sensatez y relativa autonomía están configurando el mapa actual de intercambios y aprendizajes. Sin detenernos en cada una de estas variables ampliamente tratadas por autores como Pérez Gómez (2012, 2017), nos parece necesario y en relación con la temática que se aborda, detenernos en dos de ellas: la desconexión con lo natural; y la saturación digital de información.

\section{La desconexión con la naturaleza}

Se habla con frecuencia de la importancia de la brecha digital en relación, no solo con las desigualdades de acceso, sino también con el conocimiento que se requiere en relación, a las Tecnologías de la Información y la Comunicación (en adelante, TIC) por determinados sectores de la población (Gómez y Ospina, 2002). Sin embargo, también existe una hiperconexión digital que está transformando la relación de los aprendices con el entorno y sobre todo con el entorno natural generando lo que Louv (2008), cofundador de la Fundación Children and Nature Network, denominó como trastorno por déficit de naturaleza, por lo que implica en las desigualdades de acceso a lo natural y por tanto a entender el complejo ecosistema de relaciones que nos mantiene vivos (Braidotti, 2015; Snaza et al., 2016). El confinamiento ha venido a acentuar una tendencia social cada vez más extendida en los contextos desarrollados: la infancia pasa gran parte de su día sentada, en entornos cerrados y totalmente ajenos al medio natural. Todo ello genera problemas de salud y educativos, como la obesidad, déficit de atención, alergias, enfermedades respiratorias, hiperestimulación visual e informativa, y dificultades para desarrollar un pensamiento propio, crítico y creativo entre otros. Cada vez somos menos conscientes del vínculo necesario que el ser humano debe tejer con lo natural, vivimos conectados a las TIC y desconectados del medio natural que nos rodea, sin tomar conciencia de las importantes repercusiones que cada una de nuestras acciones cotidianas y locales, a menudo ingenuas, inconscientes e irreflexivas, tienen para el ecosistema.

Esta desconexión la creamos al desvincularnos educativa y socialmente de la naturaleza y su cuidado. En este sentido, Attali, como se citó en Alconada Mon (2020), considera urgente sustituir la economía del libre mercado por la economía de la vida, centrada en la

Reconstruyendo el conocimiento práctico en confinamiento. Una experiencia de enseñanza en la formación inicial de docentes. Soto, Maldonado-Ruiz, Márquez-Román \& Peña. 
atención y el cuidado de las personas, donde los sectores prioritarios tienen que ver con el cuidado de la alteridad (humana y natural).

\section{La influencia de los Big Data y la saturación de la información}

Esta externalización intencionada de lo natural se alimenta de un discurso que juega con el relativismo para saturar los sentidos y la capacidad de discernimiento de una población cada vez más perpleja. En tiempos de crisis, la mayoría de los medios de comunicación y las redes sociales en manos de las corporaciones privadas extienden interpretaciones interesadas hasta el límite de propagar la mentira y utilizar el miedo y la ansiedad de la población para imponer, sin demasiadas resistencias, sus criterios y sus políticas impopulares (Klein, 2019). En esta atmósfera informacional no podemos olvidar la reciente presencia de los Big Data, que en función del uso que le demos, pueden ofrecer oportunidades o limitarnos las posibilidades de contraste a través de los ecos informacionales o burbujas cerradas a las que somos expuestos en las múltiples y diferentes redes sociales (Pérez Gómez, 2020).

Vivimos una apoteosis digital, que facilita y traslada el intercambio laboral y educativo, incluso el sanitario, hacia nuevas estructuras de relación social como es el teletrabajo, el telecomercio, la telenseñanza. Las enseñanzas de la vida y las costumbres del pasado no son suficientes para afrontar los desafíos del presente y las exigencias del futuro (Wells y Claxton, 2002). Como el resto de las instituciones sociales, también la escuela y la universidad se encuentran en el foco de este debate $y$, los docentes que en otra época hemos disfrutado del privilegio del conocimiento, nos encontramos ahora sumidos en la perplejidad, a la búsqueda del sentido y utilidad de lo que hacemos y enseñamos. No podemos seguir enseñando como Sócrates a generaciones que viven en línea, conectados con sus smartphones, redes sociales y videojuegos (Beard, 2019).

En definitiva, la conciencia de la extraordinaria complejidad del escenario actual requiere también respuestas educativas de análoga complejidad.

\section{Retos educativos en tiempos de incertidumbre}

Las exigencias y urgencias de una realidad tan extraordinaria como la que estamos viviendo han dejado al desnudo no solo las débiles y desiguales estructuras sociales, sino también los sistemas escolares actuales, altamente mediatizados por intereses ideológicos y políticos y con una financiación a la cola de Europa según el Instituto de Estadística de la Unesco (2015).

La pandemia ha trasladado la escuela y la universidad al hogar. El prolongado confinamiento ha obligado a hacer una transición digital de urgencia que ha puesto de manifiesto tanto la relevancia de la enseñanza virtual como la magnitud de la fractura digital: las insuficiencias estructurales y las deficiencias en la preparación de los docentes para trabajar en dichos escenarios (Gewertz, 2020). Así, además de un pobre y desactualizado conjunto de recursos tecnológicos inaccesibles para todos y todas emerge la complejidad de cómo atender educativamente a los estudiantes a pesar de la distancia ${ }^{1}$.

\footnotetext{
${ }^{1}$ Según el informe de la plataforma de aprendizaje en línea Perply, donde se han analizado la situación de 30 países de la OCDE, en relación con la accesibilidad a la educación en línea, la accesibilidad a Internet y los ambientes de e-learning, España se encuentra en la posición 24, a pesar de que tiene el $5^{\circ}$ internet más rápido de la OCDE - según datos de Speedtest Global Index-, por delante de países como Noruega (Muñoz Vita, 2020).
}

Reconstruyendo el conocimiento práctico en confinamiento. Una experiencia de enseñanza en la formación inicial de docentes. Soto, Maldonado-Ruiz, Márquez-Román \& Peña. 
El proceso educativo se produce, como hemos descrito anteriormente, en un contexto social de interacciones ilimitadas, complejas y emergentes. Esto abre un espacio incierto e impredecible al que no podemos responder como docentes de una forma simple, mecánica y estandarizada. Coincidimos con Pérez Gómez (2019) cuando establece la necesidad de generar contextos donde los sujetos desarrollen su propio proceso de construcción de la identidad personal, y para ello se hace necesario generar procesos que permitan:

Aprender a vivir en la incertidumbre y manejar la fragilidad y el cambio permanente, como seres humanos capaces de dialogar con la realidad de una forma empática y crítica, con capacidad para indagar, pensar y actuar de forma cooperativa e interpretar la complejidad como sistemas holísticos inagotables.

Promover el cuidado y la cooperación, como construcción compartida de comunidades solidarias y compasivas que facilite una convivencia saludable y la supervivencia sostenible de una sociedad más humana. Necesitamos estimular la conciencia ecológica y promover un modelo económico equitativo y sostenible que persiga la primacía del bien común y el cuidado de las personas y del medio natural (Garret, 2020; Cruz, 2020).

Cultivar la sabiduría transitando de la información al pensamiento crítico, práctico y creativo. En esta era de supercomplejidad, el problema no es la carencia de información sino la calidad de dicha información y la necesidad de discriminar el conocimiento de la charlatanería o de la denominada postverdad. La enseñanza debe promover el aprendizaje de aquellos conocimientos, habilidades, emociones, actitudes y valores que ayuden a cada individuo y cada grupo a diseñar y experimentar su camino, su singular proyecto de vida. El concepto de sabiduría implica necesariamente la integración, la coherencia y la honestidad entre las teorías proclamadas y las experiencias vivenciadas. Se trata, por tanto, de buscar la coherencia entre el decir, el pensar y el hacer en la educación.

De este modo no podemos desaprovechar la oportunidad de comprender, analizar y disfrutar educativamente la potencia de los escenarios virtuales analizando a fondo sus luces y sus sombras. La etapa de confinamiento no solo ha puesto en cuestión al sistema, sino también a nosotros como docentes, es decir, a la formación docente. Como propone Bain (2006), el docente tiene una clara función de ejemplificación testimonial y esta función, para lo bueno y para lo malo, es ineludible. Necesitamos prepararnos para que la incertidumbre no nos paralice e impida descubrir, no solo las sombras de las TIC sino también sus potencialidades. La enseñanza a distancia no tiene por qué ser distante. Así lo ponen de manifiesto diferentes e interesantes proyectos y experiencias promovidos en lugares, instituciones y organismos diversos que han intentado atender esta difícil e incierta situación. Como por ejemplo, el proyecto el Ministerio de Educación de China: "Suspender las clases sin parar el aprendizaje ni la enseñanza", las recomendaciones desarrolladas por UNICEF para "re-imaginar la educación" (Belmonte et al., 2020), o las interesantes y distintas historias compartidas por la Fundación Teach for All en su programa \#DontStopLearning, donde maestros y maestras, estudiantes y familias proponen alternativas creativas para garantizar que los niños y niñas, especialmente aquellos y aquellas en comunidades marginadas, no dejen de aprender con sentido.

\subsection{La necesaria transformación del conocimiento práctico: un reto para la formación inicial}

Atender a estos retos requiere transformar o reconstruir nuestros saberes docentes para dialogar con la complejidad, sin embargo, ¿qué significa hoy reconstruir nuestros

Reconstruyendo el conocimiento práctico en confinamiento. Una experiencia de enseñanza en la formación inicial de docentes. Soto, Maldonado-Ruiz, Márquez-Román \& Peña. 
saberes?, ¿simplemente incorporar informaciones y conocimientos nuevos?, ¿cómo podemos ponerlos en relación con lo que ya sabemos? En la formación inicial, los estudiantes de docentes ingresan con un bagaje experiencial escolar y escolarizado que condiciona sus aprendizajes y por tanto las posibilidades de reconstruir no solo lo que saben sino de incorporar los saberes nuevos en saberes útiles y prácticos.

Como docentes solemos visitar los nuevos territorios con el mismo equipaje. Tenemos dificultades para atender los retos y demandas que los ambiguos e inciertos contextos ponen ante nosotros. Estos problemas prácticos plantean dilemas para los que, en la mayor parte de las ocasiones, no existen soluciones claras. Generalmente, cuando los docentes se encuentran ante una realidad emergente, lo primero que hacen es valorarla emocional y cognitivamente bajo el tamiz de las creencias personales, y activar mecanismos de percepción, interpretación, toma de decisiones y actuación, no necesariamente conscientes, que componen su mochila personal y profesional implícita (Pérez Gómez, 2020). Es el territorio del conocimiento práctico.

En estos momentos existe una intensa y abundante conversación global sobre cómo entender, describir y diseñar la formación del profesorado (Brown, 2017) desde las "teorías del activismo social"; "teorías de la educación post-coloniales, post-estructurales y post-modernas"; "estudios de ciencias feministas, pragmatismo revisionista y teorías indígenas contemporáneas del conocimiento"; "enfoques multiculturales y críticos para la formación del profesorado que enfatizan la realidad de las identidades socioculturales, de raza, identidad cultural y género"; "la formación docente como práctica democrática"; "enfoques críticos: centrados en el aprendizaje / centrados en la persona"; "enfoques sistémicos", etc. Un nutrido debate que apenas ha calado, salvo dignas y relevantes experiencias aisladas, en la formación inicial de docentes.

Nuestra práctica e investigación como formadores del profesorado, recoge los aportes que supuso la aproximación interpretativa, para reconocer y analizar la complejidad de la práctica docente y su capacidad para sensibilizar a los profesionales sobre los matices de los procesos educativos (Jackson, 1991; Van Manen, 2015; Grossman, 1990). Y la perspectiva de la Teoría Crítica, que nos permite entender la influencia del poder en la experiencia individual y grupal y en la comprensión de lo que para la ciencia social cuenta, como preguntas relevantes de investigación.

Pero también y, sobre todo, nos detenemos y profundizamos en la investigación sobre el conocimiento práctico del docente, entendiendo que además de estar sensibilizados sobre el carácter socialmente construido de nuestra comprensión de los procesos educativos no podemos dejar sin explorar el tipo de conocimiento útil que el profesor puede adquirir al reflexionar sobre el curso de su propia experiencia (Rosiek y Gleason, 2017).

\section{El habitus pedagógico y la construcción del pensamiento práctico}

La formación inicial del profesorado, en general, sigue promoviendo una enseñanza convencional, artesanal o técnica (Schön, 1992). Una clara tendencia escolástica en el sentido en el que Freinet utilizaba el término, donde la toma de apuntes, la memorización y el examen, no facilitan la adecuada relación entre la teoría y la práctica, ni garantizan la construcción de conocimiento profesional útil, sino que de forma efímera barniza las teorías declaradas de los estudiantes sin que apenas cale en sus teorías en uso, es decir en aquellos conocimientos y estrategias que ponen en acción cuando se encuentran en el escenario del aula (Zeichner, 2010; Pérez Gómez, 2017; Elliott, 2012; Korthagen y Nuijten, 2018; Darlin-Hammond y Oakes, 2019).

Reconstruyendo el conocimiento práctico en confinamiento. Una experiencia de enseñanza en la formación inicial de docentes. Soto, Maldonado-Ruiz, Márquez-Román \& Peña. 
La Teoría, imprescindible en sí misma, no cala, no se in-corpora, ni contribuye a mejorar la práctica (Webster-Wright, 2009) aunque la mayor parte de los planes de estudio de maestros siguen proponiendo, explícita o implícitamente en la concreción de sus planes de estudio, primero la Teoría y luego la Práctica (Clandinin y Connelly, 1995). Sin embargo, desde hace al menos veinticinco años, la literatura pedagógica (que "enseñamos" a los futuros maestros) afirma insistentemente que el conocimiento profesional se construye desde la práctica y no solo ni principalmente desde la teoría.

Desde los planteamientos de Dewey que defienden la enseñanza como una forma de indagación y creación de conocimiento, las posiciones constructivistas neopiagetianas y neovigoskianas, así como desde la amplia difusión de los significativos trabajos de Schön (1992 y 1998), Argyris (1999) y Korthagen (2010) sobre la importancia del pensamiento práctico, se consolida una alternativa epistemológica que entiende la formación de los ciudadanos y de los docentes en particular, como un proceso permanente de reconstrucción conceptual y reestructuración continua de los modos de comprensión y actuación, al calor de las experiencias y reflexiones que cada uno vive con los objetos, personas, ideas y contextos que rodean su existencia personal y profesional.

De forma sintética (Pérez Gómez, 2012, 2017; Soto et al., 2015; Pérez Gómez y Soto, $2019)^{2}$, podríamos definir el conocimiento práctico o conocimiento en la acción, como un conjunto de dimensiones inconscientes -creencias, conocimientos, habilidades, emociones, actitudes y valores- que operan de forma automática en la manera que tenemos los docentes de percibir, interpretar, tomar decisiones y actuar en el escenario complejo de las interacciones de aula. Un sistema de procesamiento y respuesta rápido, automático, útil y eficaz pero epistemológicamente cargado de prejuicios, lagunas y contradicciones, fruto de la experiencia biográfica de cada sujeto en el contexto que rodea su existencia.

Sin embargo, el pensamiento práctico incluye el conocimiento en la acción más el conocimiento reflexivo sobre la acción. Es decir, está constituido por todos los recursos (conscientes e inconscientes) que utilizamos los seres humanos cuando intentamos comprender, diseñar e intervenir en una situación concreta de la vida personal o profesional. Son recursos cognitivos y afectivos plurales, lentos y reflexivos, que toman en consideración todas las variables posibles para el análisis de los fenómenos y situaciones, así como la previsión de consecuencias de los diferentes cursos de acción que el sujeto puede adoptar en el entorno donde habita.

Vivir y construir una experiencia educativa requiere la transición permanente y cíclica del conocimiento al pensamiento práctico y viceversa. Por ello, ser docente exigirá programas y estrategias que ayuden a crear la integración más flexible, abierta y potente entre estas dos estructuras donde la reflexión, entendida como consciencia informada, será clave para que este conocimiento práctico se constituya en pensamiento práctico. Cabe insistir una vez más que el pensamiento práctico no supone el desprecio y desconsideración del conocimiento práctico, sino su reconstrucción consciente.

Para facilitar esta reconstrucción nos parece especialmente importante tener en cuenta y detenernos en tres conceptos clave: la teorización de la práctica, la experimentación de la teoría y el concepto de habitus de Bourdieu (2008).

\footnotetext{
${ }^{2}$ En estas lecturas se puede acceder a una mayor profundización en los conceptos mencionados y en cómo lo desarrollamos en los procesos de formación inicial y permanente desde nuestro grupo de investigación. Reconstruyendo el conocimiento práctico en confinamiento. Una experiencia de enseñanza en la formación inicial de docentes. Soto, Maldonado-Ruiz, Márquez-Román \& Peña.
} 
Teorizar la práctica, Practical Theorizing (Hagger y Hazel, 2006) o la reflexión sobre la acción (Schön, 1998), pretende re-conocer y comprender los recursos explícitos e implícitos que nos constituyen, alimentan y condicionan en relación con el núcleo más profundo de nuestras creencias y de su compleja identidad (Korthagen, 2005) dentro de un contexto de experiencia vivo. La teoría debe servirnos para explicar-nos y fundamentar nuestra acción y no solo como un adorno útil para el intercambio retórico. En síntesis, teorizar la práctica implica la reflexión del docente sobre su propia práctica a la luz de las experiencias educativas más relevantes y de los resultados de la investigación educativa más consistentes, pero no es lo mismo que pensamiento práctico.

Tal y como hemos definido, y siguiendo a Korthagen (2005, 2010), este requiere, además, convertir las nuevas teorías personales en modos concretos, sostenibles y ágiles de interpretación y actuación, es decir, la experimentación de la teoría. Es decir, este proceso no solo transforma nuestra percepción sobre lo que sucede en la emergencia del contexto, cuestionando creencias biográficamente consolidadas, sino que transforma nuestros actos y en definitiva nuestras competencias docentes. Entendemos éstas como sistemas complejos de reflexión y acción en las condiciones inciertas de la práctica profesional.

El desarrollo de competencias de alto nivel requiere contextos complejos, climas de confianza, y tiempos largos para permitir el razonamiento lento, el abordaje interdisciplinar de situaciones, casos, problemas y proyectos y la integración del conocimiento personal de cada aprendiz (Webster-Wright, 2009).

Por tanto, diseñar estos contextos complejos requiere atender también a lo que Bourdieu (2008) denomina como habitus, un conjunto de disposiciones sociales e individuales, un territorio intermedio entre las estructuras materiales y los patrones subjetivos que constituye la atmósfera material y simbólica que rodea el crecimiento de cada ser humano. El habitus hace que personas de un grupo social similar tiendan a compartir estilos de vida parecidos, con la suficiente porosidad para que, al mismo tiempo, permita construcciones singulares. Es un espacio donde lo objetivo y lo subjetivo, lo común y/o singular, se precipitan en modos concretos y habituales de relaciones interpersonales que presiden la atmósfera onmipresente de nuestros intercambios con la naturaleza, con los demás y con nosotros mismos. Una estructura que a la vez orienta y filtra nuestra percepción y actuación en el mundo.

¿De qué está compuesto el habitus? ¿Cuál es su naturaleza? La antropología, la sociología, la economía, la política y el resto de las ciencias sociales, de las humanidades y de las artes ofrecen aportaciones sustanciales y contingentes para entender el hábitat y el habitus que rodea, influye y condiciona los hábitos, de todo tipo, que adquiere y construye cada individuo. Cada habitus, como construcción social, está configurado para cumplir unas determinadas funciones sociales y no otras, con un sentido y un propósito, explícito u oculto, más o menos coherente, mejor o peor organizado, pero, sin duda, con una potente intencionalidad.

El habitus son disposiciones que se repiten, un conjunto complejo y reiterado de habilidades, actitudes, emociones y valores que traduce y conecta directa y sensitivamente los elementos más objetivos de la cultura con nuestros sentidos, convirtiendo el proceso de aprendizaje del habitus en un proceso de in-corporación de hábitos. El habitus se aprende mediante la representación y mediante la figuración y, en

Reconstruyendo el conocimiento práctico en confinamiento. Una experiencia de enseñanza en la formación inicial de docentes. Soto, Maldonado-Ruiz, Márquez-Román \& Peña. 
todo caso, es decisiva la participación del cuerpo $^{3}$. Por ejemplo, la percepción de la música es fundamentalmente figurativa y no representacional. Nos llega o no nos llega, nos hace vibrar el cuerpo, erizar la piel, o no, en función de la capacidad que tiene para incorporar emociones en su interpretación.

El habitus es el medio por el que transitan las emociones ligadas a la experiencia; de ahí la importancia y relevancia que tienen para cada uno de nosotros y nosotras los aprendizajes in-corporados en nuestro proceso de socialización como sujetos. El habitus sería como un conocimiento práctico grupal y/o colectivo aprendido de forma espontánea y generalmente inconsciente. Sin embargo, también es cierto que, en el desarrollo evolutivo de cada individuo o grupo humano, aparecen ocasionales quiebras, rupturas, contradicciones, divergencias que abren grados de libertad, que permiten la progresiva singularidad de la urdimbre que cada uno teje a partir de la trama recibida, de los patrones comunes heredados. Tan decisivo será comprender la trama externa común, como la urdimbre interna singular. No puede entenderse la complejidad de cada ser humano sino desde el respeto a su consideración como sistema vivo, orgánico y mental, una compleja combinación de elementos que interaccionan entre sí de manera peculiar dentro del propio ecosistema del que forman parte (Bronfenbrenner, 1999; Godfreyy Brown, 2019 como se citó en Pérez Gómez, 2020).

¿Cómo deconstruir aquellos hábitos de los que ni siquiera somos conscientes pero que condicionan nuestra manera de percibir, estar y actuar en el mundo? ¿Qué habitus hemos vivido como discentes en la escuela convencional y hemos in-corporado como estructura estructurante de hábitos personales que condicionan nuestra manera de percibir, estar y actuar como docentes? ¿Cómo construir un habitus pedagógico en la formación inicial de docentes que contribuya a generar hábitos informados y sensibles en los estudiantes de maestro/a?

Para potenciar la construcción del pensamiento práctico en cada experiencia docente necesitamos comprender el habitus educativo colectivo, dominante y el hábito particular incorporado de los estudiantes en formación. Desde ahí podemos contribuir a que ellos y ellas tomen conciencia de él y puedan reconsiderar el valor epistemológico y existencial de estos modos aprendidos de entender y reaccionar, así como reformular los que consideren inadecuados o tóxicos para su desarrollo a través de los dos procesos claves: teorización de la práctica y experimentación de la teoría.

Existen múltiples modelos que proponen diferentes estrategias narrativas, reflexivas, generalmente al margen de la práctica o analizando la práctica desapegada del cuerpo del docente en formación, que intentan tejer la teoría y la práctica. Sin embargo, y a pesar de que se modulan discursos y comprensiones del hecho educativo, no consiguen calar en las prácticas docentes cuando estos estudiantes de maestros/as se enfrentan a las emergencias cotidianas de un aula. Han sido teorías útiles, analizadas y comprendidas pero que no se han convertido en habitus y en hábitos pedagógicos para el estudiante en formación. Las propuestas teóricas que consideremos valiosas han de materializarse en

\footnotetext{
${ }^{3}$ Esta mirada converge con la tendencia actual de distinguir e integrar la epistemología de la representación con la epistemología de la figuración. La emoción y el afecto están en el centro de las reflexiones...reconociendo el papel de las formas sensoriales de conectarnos con el mundo. Las epistemologías figurativas incluyen una forma incorporada de cognición. Un bucle de resonancias estéticas y afectivas.
}

Reconstruyendo el conocimiento práctico en confinamiento. Una experiencia de enseñanza en la formación inicial de docentes. Soto, Maldonado-Ruiz, Márquez-Román \& Peña. 
climas de interacciones, en procedimientos y rutinas que presiden los encuentros educativos.

\subsection{Principios para una formación inicial de maestros y maestras presencial y virtual}

La formación inicial ha de poblarse de espacios de experiencia educativa estimulantes que transiten emocionalmente y nos conecten con las maestras y maestros en formación inicial y con sus singulares itinerarios vivenciales. Como hemos visto, el habitus pedagógico es un espacio donde la relación (Leeferink et al., 2015), la presencia y el vínculo con y entre los sujetos convive de forma sustancial con la teoría, un espacio donde la teoría se hace experiencia y la experiencia teoría, una teoría propia y singular que no pretende generar dogmas sino una manera singular y a la vez compartida de sintonizarnos con la educación. Como Clandinin y Connelly (2000) y Knight et al. (2015) concluyen, el aprendizaje del docente es relacional (las experiencias tienen lugar en contextos sociales), temporal (las experiencias se enmarcan a través de acciones previas e influyen en nuevas experiencias) y situacional (las experiencias se basan en situaciones).

La dimensión emocional y afectiva es igual de importante que la académica y cognitiva. El cerebro necesita emocionarse para aprender y para tener curiosidad (Pérez Gómez, 2017). La emoción es el ingrediente que permite el encendido de la conducta. O lo que es lo mismo, nadie aprende de una manera significativa y relevante (que le afecte en su vida cotidiana) a menos que aquello que ha de ser aprendido nos emocione y nos motive, es decir, algo que le otorgue un sentido y significado a lo que estamos aprendiendo, de lo contrario estaríamos ante un trámite efímero (Mora, 2014). Tan importante es el plano emocional que los últimos avances en neurociencia demuestran la estrecha relación entre los sentimientos (intangible) y la anatomía del cerebro (tangible). El proceso mental de las emociones es muy básico: se generan en el cerebro reptiliano y son racionalizadas por el neocórtex mediante los pensamientos, de manera que una emoción puede alimentar miles de pensamientos (Corbera, 2015). Por tanto y en relación con los modelos de formación docente, necesitamos transcender la figura docente para que, de manera progresiva, su labor se centre en tutorizar el aprendizaje de todos y cada uno de los aprendices, ayudando a aprender y a autorregular el propio aprendizaje en un mundo cambiante, complejo, acelerado e incierto (Pérez Gómez, 2017). Qué mejor estrategia para que los futuros docentes se impregnen de este modelo que siendo partícipes de él. Comprobando la importancia para aprender del acompañamiento de una persona que te mira a los ojos, que te tiende la mano, que te hace preguntas y sobre la que siempre prevalece el compromiso, la autoconfianza y la seguridad de que puedes hacerlo.

Para ello, necesitamos contextos que recreen la cultura de la colaboración y cooperación docente, estableciendo vínculos y relaciones tejidas de emociones, también en la virtualidad. Crear comunidades profesionales que ayuden a sostener una enseñanza activa, reflexiva y personalizada, que facilite que cada aprendiz de docente re-construya su propio proyecto docente y desarrolle su personalidad y nuevos hábitos pedagógicos de manera más completa, experimentando, descubriendo los problemas reales del contexto, en permanente interacción con la experiencia y los miembros de su comunidad (Claxton, 2008; Pérez Gómez, 2012, 2017; Beard, 2019; Andersen y West, 2020).

El docente en formación ha de aprender a leer lo social para co-construir junto con sus alumnos y alumnas un contexto donde cada uno de ellos y ellas, desarrolle sus

Reconstruyendo el conocimiento práctico en confinamiento. Una experiencia de enseñanza en la formación inicial de docentes. Soto, Maldonado-Ruiz, Márquez-Román \& Peña. 
potencialidades únicas y singulares y considere el curriculum y el contexto organizativo como variables dependientes, provisionales y contingentes a cada grupo y persona.

La formación del docente que requieren los desafíos educativos actuales ha de afrontar, por tanto, no solo la adquisición de conocimientos académicos y pedagógicos, sino la construcción lenta y experiencial de las cualidades o competencias que requiere su complejo quehacer profesional. En educación y, por ende, en la formación inicial, no nos sirven aproximaciones que no asuman este enfoque holístico, esta pluralidad viva de elementos que interactúan permanentemente. ¿Qué tipo de experiencias podemos diseñar que facilite la reconstrucción del conocimiento práctico de los futuros docentes? (Brouwer y Korthagen, 2005).

Será imprescindible repensar todos los componentes de la formación y diseñar experiencias, vivencias y procesos de reflexión sistemáticos y tutorizados sobre la práctica singular de cada estudiante o docente, que le ayuden a identificar, formular y reformular su conocimiento práctico convencional y su estéril conocimiento declarado para transformarlos en conocimiento práctico informado y fundamentado. El docente hoy día requiere desarrollar estrategias didácticas, programas y tareas que sumerjan al aprendiz en proyectos reales, presenciales o virtuales, estrechamente ligados al contexto de la práctica social o profesional y oportunos y relevantes para la comunidad social y para la formación personal y profesional del aprendiz (Korthagen y Nuijten, 2018; Pérez Gómez, 2017; Darling-Hammond y Oakes, 2019).

La interacción permanente de la práctica y la teoría conforma un bucle creativo y dinámico, que expande el conocimiento y transforma la realidad. Sentir las teorías y reflexionar sobre los sentimientos son expresiones que denotan el valor que damos a la emoción como puerta de entrada del conocimiento.

En definitiva, y como a continuación exponemos en los principios de la experiencia desarrollada, estos escenarios de formación inicial del profesorado requieren una nueva forma de concebir la función y el desarrollo profesional del profesorado, siendo conscientes de que aprender a enseñar es aprender a conocer, pensar, sentir y actuar como profesionales del aprendizaje y la enseñanza educativa.

\section{Un proyecto vivencial en la formación inicial del profesorado de infantil antes del confinamiento}

En relación con el marco teórico expuesto, e intentando experimentar y concretar los ejes expuestos, a continuación, describiremos la estructura didáctica y organizativa de nuestra experiencia de formación inicial de maestras y maestros del Grado en Educación Infantil.

Esta experiencia fue desarrollada por un grupo de cinco docentes ${ }^{4}$ de la Facultad de Ciencias de la Educación de la Universidad de Málaga. Un proyecto coordinado de tres asignaturas del segundo cuatrimestre del primer curso ("Didáctica de la Educación Infantil", "Organización en la Educación Infantil" y "Hacía una escuela Inclusiva: Modelos y prácticas"), que se inicia en el curso 2010-2011, y que, desde entonces, ha ido evolucionando y adaptándose a las demandas y retos del contexto e incorporando a nuevos docentes.

Atendiendo a la fundamentación expuesta, este proyecto tiene una estructura metodológica interdisciplinar compleja diseñada para promover el desarrollo y la

${ }^{4}$ Las autoras y autor del texto, junto con la profesora María José Serván Núñez.

Reconstruyendo el conocimiento práctico en confinamiento. Una experiencia de enseñanza en la formación inicial de docentes. Soto, Maldonado-Ruiz, Márquez-Román \& Peña. 
evaluación de aquellas competencias profesionales ${ }^{5}$ docentes que consideramos fundamentales para el profesorado de esta etapa en el siglo XXI. En definitiva, intentamos promover un habitus pedagógico que contextualice el aprendizaje para que, "en cada situación los estudiantes construyan, modifiquen o refuten los conocimientos contextualizados y desarrollen competencias a la vez situadas" (Jonnaert, 2006). Esto supone implicar al alumnado en procesos vitales auténticos que acompañen un crecimiento intelectual integrado, incorporando las diferentes dimensiones que estructuran la naturaleza de las competencias fundamentales, habilidades, actitudes, conocimientos, valores y, por supuesto, las emociones.

\section{Las finalidades}

De este modo, las competencias claves que pretendemos desarrollar tienen que ver con:

1) Diseñar y ofrecer escenarios de acción y reflexión que les permitan construir un conocimiento comprensivo, significativo e interdisciplinar sobre una realidad compleja para la que tienen que elaborar juicios argumentados y críticos y propuestas didácticas reales diseñadas desde los ojos, deseos y necesidades de la infancia;

2) Aprender a colaborar y a comunicarnos con todos los recursos posibles respetando la diversidad y discrepancia;

3) Aprender a conocernos y reconocernos a través del otro y en consecuencia autoregularnos y regular nuestro propio aprendizaje.

El fin último es formar docentes comprometidos con la educación, con una mirada respetuosa hacia la infancia, que comprendiesen el verdadero sentido y valor de la escuela y el papel que tienen como docentes en todo este proceso.

\section{Los principios}

Diseñar y recrear un habitus pedagógico requiere, por tanto, repensar cada uno de los principios que ayuden, desde esta perspectiva integrada, a crear y recrear una estructura de relaciones, intercambios y experiencias que favorezcan el encuentro pedagógico deseado. Por todo ello, nuestro objetivo inicial y sustantivo era diseñar y recrear contextos donde el alumnado pudiera vivir y experimentar, en definitiva, poner-se en acción y relación:

- La relevancia e interdisciplinariedad del conocimiento atraviesa y pone en relación los contenidos de las tres materias, a veces singulares y a veces sistémicos para comprender y analizar la práctica educativa seleccionada.

- Una estructura metodológica compleja y centrada en procesos de teorización de la práctica y experimentación de la teoría, a través de procesos de investigación cooperativa y comprometida con la mejora de la práctica escolar (Lesson Study, y Aprendizaje y Servicio). Implicar a los estudiantes en experiencias reales donde el aprendizaje cobre sentido y esté situado con una imagen de infancia real, plena y no estereotipada.

- La evaluación formativa: para hacer visible y poner en cuestión el conocimiento práctico a través del Portafolios digital. Entender la evaluación como un proceso

\footnotetext{
${ }^{5}$ Recuperamos el concepto de competencias, como cualidades humanas fundamentales (Pérez Gómez, 2012) con las que las personas nos ponemos en juego con todo lo que somos, pensamos, sentimos y queremos

Reconstruyendo el conocimiento práctico en confinamiento. Una experiencia de enseñanza en la formación inicial de docentes. Soto, Maldonado-Ruiz, Márquez-Román \& Peña.
} 
metacognitivo de reflexión sobre los aprendizajes adquiridos es una estrategia necesaria si queremos promover el desarrollo de competencias.

- La flexibilidad y apertura de tiempos, espacios, recursos y procesos. Conseguir tiempos amplios y menos fragmentados (bloques de 5 horas por asignatura), para desbordar y abrir los escenarios de aprendizaje habituales tanto en la universidad como en las aulas de Educación Infantil, verdaderos ejes de sentido del proyecto.

- Un clima de confianza y seguridad personal donde se potencie el deseo y la libertad para aprender, para comunicar sin miedo al error y sin temor al ridículo social. Tratamos de vincular autonomía y libertad junto con el compromiso y la responsabilidad manteniendo las más altas expectativas sobre todos y cada uno de ellos y ellas.

- Respetar la singularidad de cada aprendiz promocionando las relaciones interpersonales, cooperativas y participativas. Actitudes claves en el desarrollo personal: comprensión, tolerancia, generosidad y empatía.

- La coordinación docente como estructura que sostiene la complejidad de la enseñanza y el aprendizaje y que, al mismo tiempo, nos potencia como docente.

- La tutorización como estrategia: La enseñanza personalizada. Esta coordinación y el agrupamiento interdisciplinar nos permitía hacer un seguimiento cercano e interrogativo y más complejo de las vivencias y reflexiones de nuestros estudiantes ya que, gracias a ella, hemos podido disminuir de 60 a 20 la ratio de estudiantes que tutoriza cada docente.

\section{Los procesos de enseñanza}

La metodología de enseñanza y aprendizaje que veníamos desarrollando en el modo presencial tenía que sortear un contexto universitario muy estructurado y burocratizado, con inercias, condiciones y variables que generalmente dificultan en el desarrollo de estos propósitos generando un proceso continuo de imaginación, reinvención y desborde de los límites establecidos por el equipo docente.

El entramado didáctico y organizativo se establece en torno a un proceso de investigaciónacción cooperativa común para las tres asignaturas, que los y las estudiantes desarrollan en grupos de 4-6 estudiantes, a través de la Lesson Study, una iniciativa consolidada y con tradición en contextos asiáticos como Japón, China, etc., pero que en Europa y Estados Unidos es aún bastante reciente (Soto y Pérez Gómez, 2015). De este modo la comprensión, análisis y reflexión teórica gira en torno a este proceso que implica teorizar la práctica y experimentar la teoría, ofreciendo de forma compleja y con diferentes recursos y estrategias, los contenidos organizados en torno a ejes problemáticos didácticos, organizativos e inclusivos que cualquier proyecto de intervención didáctica requiere tanto para comprenderlo como para diseñarlo, desarrollarlo y evaluarlo.

Cada sesión teórico-práctica de las asignaturas se componía de una espiral reflexiva donde partíamos de la experiencia del alumnado para conectar con la teoría como forma de proporcionar una "base pedagógica sólida" al análisis de su experiencia (Atkinson, 2002), siguiendo el siguiente ciclo:

1.- La pregunta o provocación personal les animaba a repensar-se en relación al tema a tratar, a veces venía acompañada de un texto o vídeo que estimulara y situara la reflexión. El propósito de esta pregunta personal era ayudar a hacer visibles aquellas teorías,

Reconstruyendo el conocimiento práctico en confinamiento. Una experiencia de enseñanza en la formación inicial de docentes. Soto, Maldonado-Ruiz, Márquez-Román \& Peña. 
creencias, conceptos y experiencias sobre educación que se mantenían por debajo de la conciencia, una manera de evidenciarlos y de generalmente, descubrir su limitada potencialidad para interpretar la compleja realidad educativa. Un aprendizaje de sí mismas con cada uno de los ejes temáticos que introducimos en el marco de las tres asignaturas y que debían subir a su diario personal en el portafolio virtual.

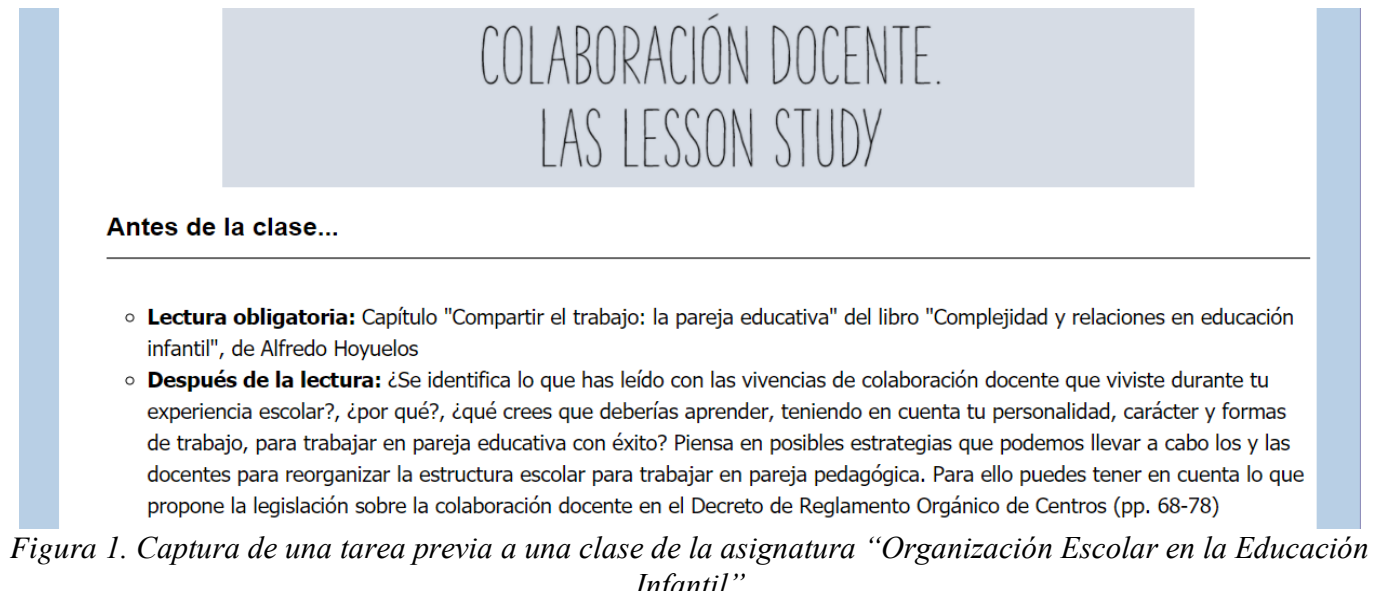
Infantil"

2.- En segundo lugar, está el momento de encuentro: clase magistral abierta al debate, indagaciones por parte del alumnado, la conferencia de un invitado/a, una película, corto o documental, etc. Así profundizábamos en la comprensión del tema o problema propuesto a través de esquemas que analizaban desde diferentes miradas y perspectivas lo que la investigación pedagógica nos aporta. Durante estas sesiones a menudo se introducían dinámicas de grupo que intentaban -mediante el juego de roles, las simulaciones, la reflexión a partir de un cuento o un hecho- relacionarlas e implicarlas emocionalmente con la temática.

3.- En el tercer momento, el grupo de 4-6 estudiantes tenía la misión de resolver el interrogante o cuestión que se les había planteado en relación con el tema del día, o generalmente, con una tarea de aplicación de esa teoría a su proyecto de Lesson Study. El contraste con otros, es decir, establecer debates dialógicos a cuestiones críticas que inviten a posicionarse, puede convertirse en momentos idóneos para descubrir las disposiciones subjetivas de su conocimiento práctico, es decir conectar con la dimensión política o ideológica, según Hoyuelos (2011), de sus identidades docentes; entendiendo que, las y los profesionales que "trabajan juntos en comunidades de apoyo tienen niveles más altos de autocomprensión, compromiso, desempeño y pertenencia" (LePage et al., 2005, p. 336).

A lo largo de la presentación hemos hablado de los diferentes tipos de familias con los que nos podemos encontrar en nuestras futuras aulas: [...]. Imaginad que vuestros niños y niñas se interesan por saber un poco más sobre esta diversidad de familias: "¿un hombre puede también enamorarse de otro hombre y tener bebés?", "¿cómo pueden dos hombres tener un bebé?", pregunta Eva.

Ante esta situación os planteamos lo siguiente: ¿sería necesario contactar con las familias de estos niños y niñas antes de adentrarnos en este u otros temas?, ¿creéis que debemos informar de los contenidos que se abordan en clase?, ¿qué poder de decisión creéis que deberían tener los padres/madres/tutores sobre estos contenidos? Y, en el caso de que consideréis necesario informar sobre ello, ¿en qué dirección deberemos orientar esa comunicación y relación con las familias?, ¿de

Reconstruyendo el conocimiento práctico en confinamiento. Una experiencia de enseñanza en la formación inicial de docentes. Soto, Maldonado-Ruiz, Márquez-Román \& Peña. 
qué forma se os ocurre que ambos contextos (escuela y familia) podrían coordinarse para que el proceso educativo de los niños y niñas sea lo más rico y coherente posible? [Pregunta colectiva planteada en el marco de la asignatura "Organización Escolar en la Educación Infantil”, 26.03.2020]

4. Finalmente, el trabajo de todos los pequeños grupos se ponía en común en una asamblea general donde se contrastaba la pluralidad de perspectivas, interpretaciones y acciones que suscita un mismo problema. Este contraste permanente partiendo del yo y encontrándonos con el grupo de iguales aportaba sentido a su aprendizaje y provocaba interesantes debates, síntoma de la conexión profunda que se empezaba a establecer.

5. Además de estas sesiones teórico-prácticas, proponíamos otras tareas y encuentros de conexión entre la experiencia y la teoría como eran los encuentros con libros biográficos o de prácticas escolares concretas. Es lo que denominábamos en la asignatura Hacia una Escuela Inclusiva: "Escuchar al otro/a dentro de mí"; o las "Historias de aula" en las asignaturas de Didáctica y Organización escolar, nuevas oportunidades de acercarlas al encuentro emocional y personal con lo educativo. En resumen, estas obras, relatos y testimonios mostraban de una manera evidente cómo la pedagogía "escapa del mundo de las palabras" (Van Manen, 1998) para tener un sentido en la profesión.

[...] pensaba que los niños y niñas eran como esponjas y que no eran tan autónomos, que dependían mucho de su maestra o maestro, pero gracias a este libro he aprendido que esto no es así, los niños son joyas, son piedras preciosas, llenos de ganas de aprender por sí solos. [Samanta | Tarea "Historias de aula"].

Además de las estrategias expuestas para el bloque teórico práctico, organizamos otras estrategias más complejas y que les ayudaban a transitar no solo la argumentación teórica de su experiencia sino también la necesaria experimentación de la nueva teoría: el portafolios digital y la experiencia reflexiva de la Lesson Study.

Todas estas propuestas eran recogidas en sendas guías de orientación [Fig. 2] que pretendían dar a conocer la esencia de cada tarea individual o grupal ${ }^{6}$. Estas guías, además de favorecer la gestión autónoma del alumnado a lo largo de toda la experiencia y hacer más fácil el terreno interdisciplinar que estaban experimentando, fueron muy útiles de cara a nuestra propia coordinación.

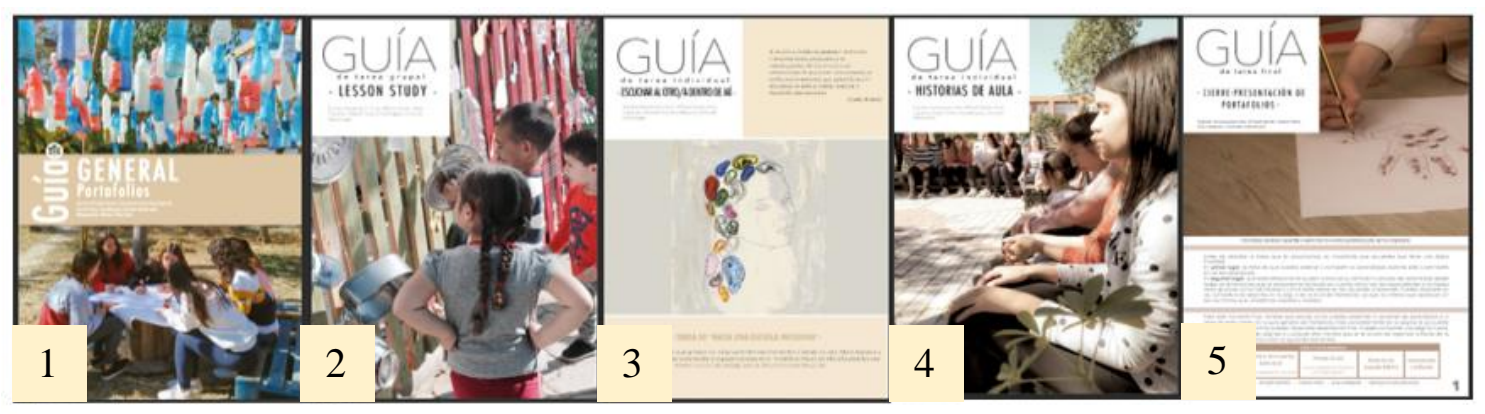

Figura 2. Visual con las guías disponibles para el alumnado.

\section{El portafolios virtual}

\footnotetext{
${ }^{6}$ Guía para la elaboración del portafolios individual (1); Guía para el trabajo grupal basado en un proceso de Lesson Study (2); Guía para la tarea específica de la asignatura de Hacia una escuela inclusiva "Escuchar al otro/a dentro de mí" (3); Guía para la tarea específica de las asignaturas de Didáctica y Organización escolar "Historias de aula" (4); Guía para la elaboración de la tarea final de cierre del portafolios (5). Ésta última se la mostramos tres semanas antes de la finalización de las clases.

Reconstruyendo el conocimiento práctico en confinamiento. Una experiencia de enseñanza en la formación inicial de docentes. Soto, Maldonado-Ruiz, Márquez-Román \& Peña.
} 
La presencia del portafolios, y en concreto del diario de aprendizaje que acompaña todo el proceso, permite que "los conceptos y relaciones que se han formado mentalmente puedan concretarse escribiéndolos, dibujándolos o explicándolos verbalmente; esto los hace más tangibles y manejables" (Korthagen y Lagerwerf, 2008, p. 191). Además, les permite adquirir el hábito de visualizar su evolución, un proceso complejo, novedoso y costoso inicialmente, pero valorado finalmente por las estudiantes.

Un portafolios donde, además de texto, pueden combinar vídeos, imágenes, fotografías, infografías o enlaces a otras webs, que como avanzaba la epistemología figurativa, abren la puerta a otros formatos sensoriales que les ayudan a conectarse con su propio universo de creencias y experiencias. Sin embargo, esta reflexión íntima y personal se hace más profunda si es acompañada con delicadeza. Entendemos, en este sentido, la retroalimentación como un diálogo a dos voces que, a modo de espejo, ayuda a reconstruir, o al menos identificar, de modo consciente aquellos elementos que componen sus teorías implícitas (Pérez Gómez, 2017) sobre lo que significa ser maestra de Educación Infantil.

El hecho de que nos propusiesen realizar un diario [...] era una cosa que me costaba bastante realizar al principio debido a que nunca me habían propuesto desarrollar uno. Sin embargo, conforme ha ido pasando el tiempo he podido apreciar la gran evolución que he tenido al respecto. [...] Aparte de los conocimientos que he ido adquiriendo, también he podido expresar cuánto me han costado comprenderlos, qué me ha permitido entenderlos, cuáles son mis miedos, qué inquietudes me provocan, etc. [Beatriz | Trabajo final]

Finalmente, el proyecto de las tres asignaturas culmina con la presentación final del portafolios como resultado del recorrido de aprendizaje que incluye una autoevaluación y autocalificación.

\section{La Lesson Study como proceso de reconstrucción del conocimiento práctico}

La Lesson Study (LS a partir de ahora) se convertía en el hilo conductor del proyecto. Es un proceso de siete fases de investigación-acción y mejora de la práctica que desarrollan en grupos cooperativos que incorpora, el diseño y desarrollo de una Lección Experimental, así como el estudio de la misma (Soto y Pérez Gómez, 2015). La LS, puede considerarse un contexto privilegiado para aprender a ser docente por tres razones:

- En primer lugar, porque rompe el aislamiento de los docentes en todas las fases del desarrollo de su práctica: diagnóstico, diseño, planificación, ejecución y evaluación.

- En segundo lugar, porque mediante la cooperación arropa a cada agente implicado en el complejo viaje hacia la transformación de sus creencias, actitudes y hábitos extraordinariamente resistentes al cambio (Lipton, 2016).

- En tercer lugar, porque al vincular la transformación del pensamiento pedagógico de los docentes a la experimentación curricular concreta, como la defendía Stenhouse, permite transformaciones innovadoras y duraderas basadas en evidencias, tanto del curriculum y la enseñanza como de los agentes implicados en la creación escenarios ecológicos que consideremos educativos.

En definitiva, y desde nuestra experiencia, la LS puede convertirse en un habitus pedagógico clave para que cada futuro docente reconstruya su conocimiento práctico: cuando analiza las características de las necesidades del aula donde se desarrollará la experiencia, debate el diseño de intervención, identifica la calidad y coherencia de sus

Reconstruyendo el conocimiento práctico en confinamiento. Una experiencia de enseñanza en la formación inicial de docentes. Soto, Maldonado-Ruiz, Márquez-Román \& Peña. 
hábitos docentes, valora los efectos de su práctica en el aprendizaje de los estudiantes y propone y experimenta alternativas de mejora de la propuesta curricular y de su propio desempeño como docentes en relación con niños y niñas de escuelas cercanas y que invitábamos a nuestra Facultad de Ciencias de la Educación. Una situación propicia para que los encuentros con la realidad se convirtieran en estímulo reflexivo permanente ¿Qué debemos tener en cuenta para diseñar una sesión didáctica? ¿Cómo diseñarla? ¿Cuáles serían las finalidades? ¿Cuál es mi papel como docente? ¿Para qué niños y niñas y cómo podríamos conocer sus intereses y necesidades? ¿Qué temáticas, materiales y recursos serán adecuados y conectarán con sus intereses? ¿Cómo podemos analizar y evaluar la experiencia?

Las evidencias recogidas durante varios años ${ }^{7}$ mostraban que no solo era de interés para nosotras y nosotros como formadores, sino y sobre todo, para nuestras estudiantes, ofreciendo momentos reveladores de transformación de su conocimiento práctico:

Porque vincularlos directamente con la realidad para la que se están formando motiva:

El hecho de que fuera un diseño para niños y niñas reales hizo que lo tomara con más entusiasmo porque en el primer cuatrimestre era como: "¿para qué estoy haciendo esto?" [África | Entrevista post grupal | 13/06/2019]

Porque investigar sobre su propia práctica les ayuda a hace visible la infancia y su relación con ella:

Nos creemos que los niños no son capaces de hacer ciertas cosas, e intervenimos antes de tiempo porque creemos que no son capaces, no porque ellos no lo sean. [Paula | Entrevista post grupal | 13/06/2019]

Porque ser docente requiere transitar del yo al nosotros:

Cada vez que íbamos pasando una fase, cada una pensaba una cosa diferente y entonces tenías que llegar a un punto en común. Y te hacía pensar porque ni tú tienes toda la verdad, ni nadie tiene toda la verdad. [...] Son todas nuestras opiniones, están mezcladas y hemos conseguido llegar a un punto en común... Somos siete personas pensando. [Luna | Entrevista post individual |21/06/2019]

Porque reflexionar sobre tu experiencia ayuda a reconstruir el conocimiento práctico:

A mí me ha cambiado la imagen de escuela, de patio, de rol docente, de infancia... Yo he cambiado mucho del primer cuatrimestre al segundo. Antes sentía que todo era más rígido, que teníamos que seguir un protocolo... yo no me imaginaba la maestra agachada, yo me imaginaba la maestra aparte. De hecho, mi madre trabaja por rincones y yo pensaba que eso era lo más innovador que podía haber porque viniendo de las mesas en fila... [Luna | Entrevista post individual |21/06/2019]

\footnotetext{
${ }^{7}$ Estas evidencias forman parte de un estudio de casos desarrollado en el curso 2018/2019 (A. MárquezRomán, I.M. Fernández García, L. Muñoz González, y E. Soto Gómez), en el marco del proyecto de investigación EDU2017-86082-P: "Lesson Studies. Escuela y universidad: Investigando la reconstrucción del conocimiento práctico en la formación inicial del profesorado".

Reconstruyendo el conocimiento práctico en confinamiento. Una experiencia de enseñanza en la formación inicial de docentes. Soto, Maldonado-Ruiz, Márquez-Román \& Peña.
} 


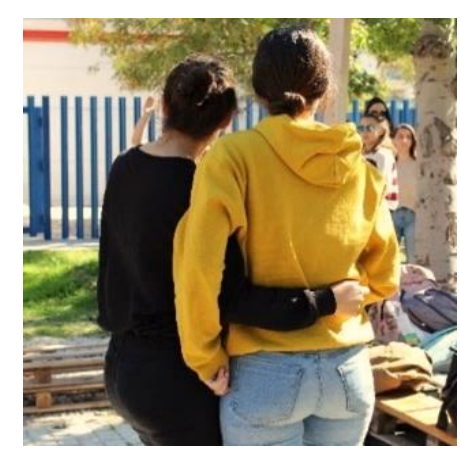

Figura 3. La docencia en sus últimos dias de presencialidad

Una experiencia que suponía un desborde continuo de los límites establecidos. Desde:

-La estructura metodológica y contextual, al poner el eje en la relación con las escuelas,

-Las fronteras disciplinares al integrar tres asignaturas distintas en un mismo proyecto.

-El sistema de evaluación, al desvincularnos del tradicional examen e incorporar un proyecto reflexivo continuo a través del Portafolios virtual que era tutorizado. ${ }^{8}$

Con estos principios y con dos nuevos docentes en formación incorporados en el equipo, iniciamos presencialmente el curso en 2020. Un mes después, se inicia el confinamiento y nuestra primera crisis como docentes: ¿Cómo acomodar la programación prevista al nuevo, incierto y extraño escenario virtual?, ¿cómo adaptar los principios de aprendizaje situado y la relación teoría-práctica vivenciada a través de una pantalla de ordenador?, ¿cómo entrar en relación con la Educación Infantil y los niños y niñas de esta etapa? En definitiva, ¿cómo facilitar el desarrollo de competencias profesionales en la distancia?

\section{Aprender y enseñar a ser docentes en casa}

Muchos de estos interrogantes fueron lugares comunes para la formación de docentes en aquellos días, e incluso en la actualidad. Sin embargo, y teniendo en cuenta las características vivenciales de nuestro proyecto, el horizonte se volvía aún más incierto que las prácticas habituales de comprensión, análisis y reproducción teórica de las Facultades de Educación. Nos tocaba ser docentes en "tiempos de incertidumbre y perplejidad" (Pérez Gómez, 2019).

A continuación, nos gustaría describir los ejes de cambio de la experiencia durante el confinamiento. Un marco cuajado de paradojas, dilemas y emociones. Ejes que, como no podría ser de otra manera, desde la naturaleza compleja y multirelacional del hecho educativo, tienen márgenes difusos y que continuamente se diluyen entre sí.

- La ignorada y omnipresente dimensión emocional: Un periodo intenso de tensiones, frustraciones.

- La reorganización constante de los tiempos, ritmos, sincronías y asincronías

- Soluciones creativas a ratios imposibles. El dilema del "gran grupo"

- El reto tecnológico: las plataformas digitales

- La emergente y urgente creación de materiales didácticos

- La importancia de esencializar el curriculum

- El dilema de la experiencia situada. La teoría y la práctica como eterno binomio de la formación en una relación sinérgica virtual

- Cuentacuentos como encuentros con otras y otros

- Los retos semanales

- Una Lesson Study inconclusa

\footnotetext{
${ }^{8}$ Puede consultarse publicaciones previas al confinamiento donde puede profundizarse en los desarrollos anteriores de la experiencia en Soto, Serván y Caparrós (2011, 2016a, 2016b), Peña, Serván y Soto (2016) Serván, Soto, Peña y Caparrós (2017), y Muñoz González y Soto (2020).

Reconstruyendo el conocimiento práctico en confinamiento. Una experiencia de enseñanza en la formación inicial de docentes. Soto, Maldonado-Ruiz, Márquez-Román \& Peña.
} 
- La tutoría de la experiencia: el acompañamiento emocional y la actitud de escucha

- La coordinación docente como sostén. Una conexión permanente

\section{La dimensión emocional: Un periodo intenso de tensiones, frustraciones $e$ incertidumbres}

En el inicio del periodo del confinamiento, y pensando que la situación sería pasajera, los cambios no fueron muy sustanciales y prácticamente seguíamos el programa presencial. Todas las sesiones, contenidos y tareas descritas, excepto las visitas a centros escolares, se desarrollaron en el mismo horario y con la misma metodología salvo el medio en el que se producían los intercambios.

Con el cierre definitivo de la presencialidad en abril de 2020, nuestro alumnado se mostraba cabizbajo y desencantado. El eje práctico de nuestro proyecto se venía abajo y tuvimos que emprender cambios sustanciales que hicieran el proceso más sostenible e ilusionante.

Debido al cambio en los acontecimientos del coronavirus, se nos ha comunicado que no volveremos a dar clases presenciales por lo que, me deprimí un poco. Una pequeña parte de mí tenía esperanzas en volver para hacer la actividad de los ambientes con los niños y niñas del colegio. Aun así, vamos a seguir trabajando la Lesson Study, ya que fue una propuesta bastante nueva y buena a mi parecer. [Nuria | Diario | 14.04.2020]

No podíamos seguir haciendo "lo mismo" porque nada era igual. Nuestro escenario y el mundo había cambiado. Se prohibía el contacto físico, y el contexto formativo requería una enseñanza con-tacto, es decir, necesitábamos acoger a nuestro alumnado de forma integral, facilitando un proceso educativo que les proporcionara un bienestar emocional que en aquellos momentos se había resquebrajado. Se trataba de rescatar la idea de una universidad que entienda la construcción de la identidad profesional como "una historia personal" (Contreras, 2010).

En definitiva, recuperar lo esencial, acogiendo los sentimientos sin urgencias. No se trataba de exigir menos, sino de valorar la importancia del sostén emocional de un grupo de estudiantes que habían vivido un sobrevenido e indefinido confinamiento.

\section{La reorganización constante de los tiempos, ritmos, sincronías y asincronías}

La revisión del proceso de enseñanza no podía obviar los tiempos y la omnipresencia de lo virtual. Necesitábamos "descomprimir" la jornada y recuperar los espacios de encuentro y diálogo con otros compañeros, docentes y profesionales externos que la virtualidad inevitablemente nos había robado. Tiempos para ofrecer un acompañamiento más cercano y estrecho. Tiempos para desarrollar propuestas diversas, retadoras y valiosas, que pasaban desde el autocuestionamiento y la reflexión con función crítica (Schön, 1992) hasta la puesta en marcha de tareas donde, bajo el contexto en el que nos encontrábamos, las alumnas y alumnos podían crear vínculo con la cultura de las infancias. Necesitábamos repensar nuestro habitus pedagógico para adaptarlo al medio virtual sin descuidar el marco de intenciones pedagógicas que compartíamos.

Además, la coordinación de tres asignaturas nos ofrecía un escenario amplio y cómodo para re-pensar creativamente los horarios, intentando diseñar una estructura que favoreciera la flexibilidad de actividades, la relevancia y, al mismo tiempo, la

Reconstruyendo el conocimiento práctico en confinamiento. Una experiencia de enseñanza en la formación inicial de docentes. Soto, Maldonado-Ruiz, Márquez-Román \& Peña. 
"descongestión" del estrés de las estudiantes. Así reorganizamos el trabajo semanal, estableciendo un día (contábamos con tres días a la semana de clase) para el abordaje de una cuestión teórica central de una de las tres asignaturas, y los otros dos días se repartían entre el trabajo autónomo de las estudiantes (bien individualmente o en grupo) y los tiempos de seminario virtual e interdisciplinar compartidos con su tutora o tutor a través de videoconferencia para trabajar y conectar experiencialmente esos conceptos.

\section{Soluciones a las grandes ratios. El dilema del "gran grupo"}

Si en el entorno presencial era difícil acompañar al grupo de 60 estudiantes y teníamos que organizar dinámicas y momentos de pequeño grupo para llegar a ellos y ellas, en el entorno virtual el grupo de 60 se fue tornando inviable si queríamos seguir promoviendo los principios pedagógicos que vertebraran nuestro proyecto. De esta manera, decidimos dividir el gran grupo en tres "grupos medianos" (20 estudiantes) un número más adecuado para realizar dinámicas habituales de la presencialidad como eran los debates. A su vez, estos tres grupos medianos se dividían en pequeños grupos de 5-6 estudiantes, en los que se realizaban la mayor parte de tareas y trabajos grupales propuestos, además de ser acompañados semanalmente de forma más personal y estrecha. Por supuesto, se seguía manteniendo el trabajo individual con las tareas iniciales antes de clase, el encuentro autónomo con la teoría (ahora adaptada a este nuevo contexto, como se expondrá más adelante), así como la realización de otras tareas ya mencionadas como son los encuentros con libros biográficos o de prácticas escolares concretas.

Más adelante las estudiantes manifestaron su necesidad de ampliar el grupo de interacción social de referencia (20 estudiantes), por lo que ocasionalmente y de forma puntual hicimos modificaciones e intercambios en estos grupos medianos que fueron muy bien acogidos por las alumnas al poder reencontrarse con tutores, compañeros y compañeras que llevaban tiempo sin ver, pero sin el desborde de las 60 estudiantes del gran grupo.
[...] me gusta más esta alternativa de trabajo ya que después de mucho tiempo hemos podido ver otras caras y hablar con otras personas a las que habitualmente no estamos acostumbrados, es por ello que ha sido muy gratificante [...]. También el cambio de docente ha estado bastante bien, ya que siempre tenemos una docente prefijada, y cada uno tiene su manera de llevar las clases y de realizar los contenidos. [María | Diario |07/05/2020].

\section{El reto tecnológico: las plataformas digitales}

Inicialmente, la ineficacia de las herramientas que se ofrecían en la plataforma propia de la universidad -el Campus Virtual-, junto con la saturación de servidores que en esos momentos sufría gran parte de la población, generó una sensación de frustración e insatisfacción en el alumnado y en nosotros mismos que nos introdujo en una dinámica de cambio, exploración y testeo constante y estresante de nuevas herramientas tecnológicas.

Hoy hemos hecho un debate muy interesante. Aunque los medios no han sido los mejores ya que constantemente se saturaba el chat, no sabía si llegaban mis comentarios y al reiniciarlo ya no podía ver las preguntas y respuestas de mis compañeras. [Helena | Diario | 17.03.2020]

A partir de ahí todo el cuatrimestre se convirtió en un laboratorio de pruebas de distintas herramientas y recursos TIC, explorando diferentes plataformas que pudieran acoger las necesidades pedagógicas de los procesos cooperativos y de tutorización que poníamos en marcha:

Reconstruyendo el conocimiento práctico en confinamiento. Una experiencia de enseñanza en la formación inicial de docentes. Soto, Maldonado-Ruiz, Márquez-Román \& Peña. 
-Para el intercambio con los pequeños grupos hicimos uso principalmente de plataformas como Skype, donde diseñamos espacios privados para cada grupo donde no estábamos presentes y que podrían servirles de salas de trabajo autónomo para el intercambio de las preguntas colectivas y diseño de sus propuestas.

-Para las sesiones con los grupos medianos comenzamos utilizando las herramientas de mensajería síncrona del Campus Virtual, pero los fallos de funcionamiento nos hicieron probar Skype, y finalmente Google Hangouts por ofrecer, en ese momento, mayores facilidades para la accesibilidad de las alumnas. En un primer momento el intercambio principal con los grupos medianos fueron los debates escritos y asíncronos. Poco a poco, como acabamos de mencionar, el vértigo y el caos tecnológico inicial se fue calmando y conseguimos retomar los debates orales sincrónicos, utilizando para ello Google Meet.

[...] creo que es una mejor dinámica para debatir, ya que en la otra plataforma se realizaba mediante escritos y no por llamada, y había con frecuencia, desviaciones de temas, y pérdidas del debate efectuado, así como aglomeraciones de mensajes que no daban tiempo a leer, para así poder participar [María | Diario |07/05/2020].

-Por supuesto seguíamos con el correo electrónico, y con las herramientas asíncronas del Campus Virtual que nos seguían siendo útiles: foros asíncronos para la resolución de dudas, subida de tareas, presentaciones teóricas, materiales complementarios, guías y vídeos explicativos de las diferentes tareas a realizar. Materiales de los que hablaremos más detenidamente a continuación. Además, la herramienta Portafolio virtual UMA seguía constituyendo la plataforma idónea para el acompañamiento profundo de las reflexiones que cada estudiante hacía en su diario, las cuales eran retroalimentadas mensualmente por su tutor/a.

Este catálogo de pruebas con diferentes softwares estaba orientado por nuestro interés en encontrar una manera accesible e intuitiva de establecer canales comunicativos reales con y entre las alumnas. Es decir, canales de comunicación espontánea, cercana y abierta, donde pudieran aflorar sus creencias más arraigadas. ¿Sería posible? La incesante experimentación nos llenaba de incertidumbre: ¿Existe alguna herramienta virtual que ofrezca per se una experiencia diferente a la réplica de un debate o seminario de la presencialidad? Una búsqueda que no podía dejar al margen la realidad contextual de nuestras estudiantes ${ }^{9}$.

Paralelamente, y con el fin de buscar espacios que motivaran y conectaran emocionalmente con las estudiantes y "alentar la reflexión para estimular el pensamiento" (Atkinson, 2002, p. 106), abrimos también una cuenta de Instagram [Fig.4] y un Canal de Youtube. Desde ahí podíamos establecer otros códigos de comunicación y sintonizar con los lenguajes propios de estas plataformas y con los de nuestras estudiantes. Momentos en los que pretendíamos desarrollar una tutorización cercana y conectada con sus intereses que además volvía a desbordar de nuevo los límites de tiempo y espacio universitario para conectar con su cotidianidad.

\footnotetext{
${ }^{9}$ La brecha digital también afectaba a nuestras estudiantes, ni el contexto o espacio destinado en sus hogares para el estudio coincidía con el lugar de conexión Wifi, ni esta era lo suficientemente estable ante la intensa demanda para generar un espacio cómodo de trabajo y relación.

Reconstruyendo el conocimiento práctico en confinamiento. Una experiencia de enseñanza en la formación inicial de docentes. Soto, Maldonado-Ruiz, Márquez-Román \& Peña.
} 


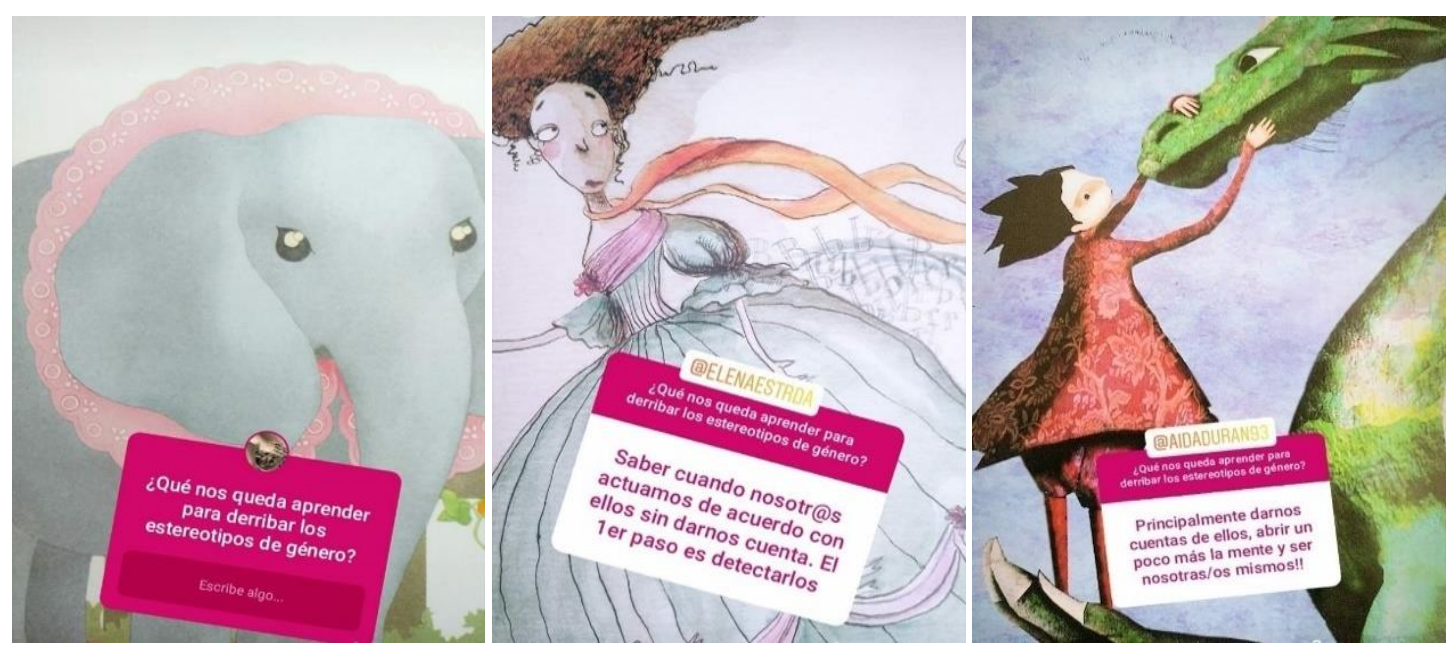

Figura 4. Capturas de una encuesta en stories de nuestra cuenta de Instagram realizada tras una sesión de "Hacia una Escuela Inclusiva" [imágenes utilizadas extraídas de álbumes ilustrados leídos con las alumnas]

\section{La emergente y urgente creación de materiales didácticos}

Con esta idea de generar un ambiente más "destensado" pero sin perder el sentido y conexión con sus vivencias, elaboramos nuevos y diferentes materiales y recursos con diferente formato, que facilitara el aprendizaje de las estudiantes en este nuevo contexto: una guía audiovisual y textual especial de orientación sobre cómo se produciría la docencia en esta nueva fase que vivimos, que incorporaba un cronograma semanal de las tareas y momentos de encuentros a modo de mapa interactivo.

A partir de ahora los profesores/as nos van a facilitar un cronograma todos los lunes para saber que tareas corresponden hacer a lo largo de las semanas. [...]. Realmente puedo decir que es una buena propuesta el dejarnos estos dos días a los distintos grupos para que realizáramos las propuestas, ya que [...] creo firmemente que la única manera de elaborarlo bien es emplear días a fondo con ello. [María | Diario | 16.04.2020]

Sin embargo, uno de los elementos sustanciales que tuvimos que transformar eran las clases y encuentros "magistrales con la teoría".

La lección magistral suponía un momento para construir un discurso colectivo (Greenwood y Levin, 2012) con las estudiantes en el que, de una manera dialógica, compartíamos también nuestra relación apasionada con el contenido y múltiples anécdotas vinculadas a este. En el contexto virtual estas sesiones no eran sostenibles, a lo sumo, debían suponer media hora de encuentro o bien vía streaming o a través de vídeos pregrabados, pero seguía suponiendo el encuentro o tratamiento masivo online con todo el grupo clase, lo que para nosotros dificultaba sustancialmente la experiencia colectiva de la presencialidad. Podían conectarse todas a la vez, pero ¿era posible generar un diálogo vivo y apasionado en el que se trenzaran autoras y autores con las percepciones de las estudiantes? Eso nos llevó a diseñar presentaciones que las estudiantes pudieran leer de manera autónoma accediendo a las cuestiones y retos que ésta misma les planteaba, que luego eran acompañadas en los grupos medianos de encuentro.

Estos materiales se diseñaron teniendo en cuenta tres principios fundamentales: una esencialización del curriculum (Pérez Gómez, 2017), el estímulo de la participación y la actividad de los estudiantes, y el cuidado estético:

Reconstruyendo el conocimiento práctico en confinamiento. Una experiencia de enseñanza en la formación inicial de docentes. Soto, Maldonado-Ruiz, Márquez-Román \& Peña. 


\section{¿Qué es un recurso?}

Todo aquello que puede usarse en la escuela con finalidad educativa aunque no haya sido necesariamente construido con ese fin. Son mediadores entre lo que las niñas y los niños saben y la realidad, un vehículo para descubrir el entorno y, en definitiva, aprender.
Recursos materiales

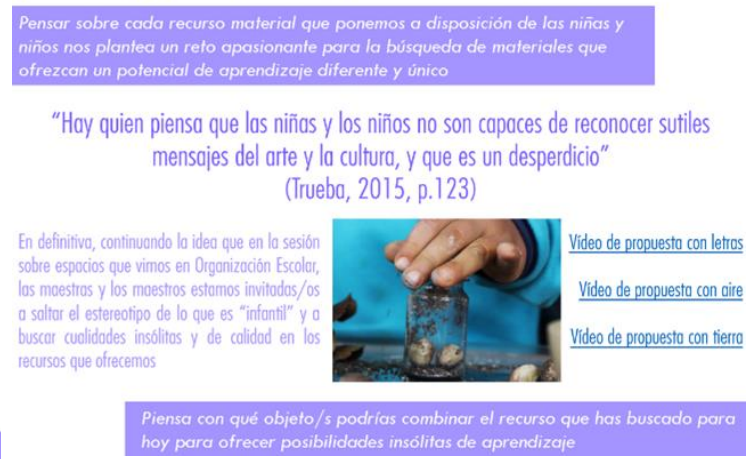

“Hay quien piensa que las niñas y los niños no son capaces de reconocer sutiles (Truebo, 2015, 123 .
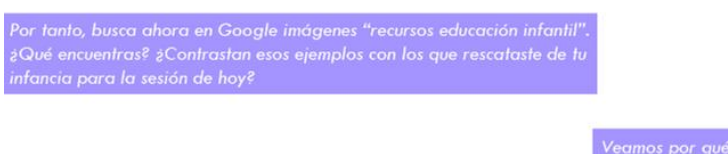

Figura 5. Diapositivas extraídas de la presentación sobre recursos educativos de la asignatura de "Didáctica de la Educación Infantil"

A pesar del esfuerzo realizado para esencializar el contenido a tratar en cada uno de los materiales elaborados para provocar este diálogo autónomo con los textos, tuvimos dificultades para acompasar los ritmos individuales con los tiempos colectivos. Una hora de tiempo para encontrarse con la presentación no era suficiente, por lo que a raíz de las reflexiones y algunas tensiones con las estudiantes tomamos conciencia de lo difícil que era para nosotros como docentes la máxima de "menos es más":

Los PowerPoints son demasiado extensos y no hay tiempo para reflexionar en la hora que nos dejáis para hacerlo, y siempre tenemos que pasar la tarde con el ordenador. [Comentario anónimo | Evaluación final].

Sobre todo, porque diseñamos estos materiales para convertirse en encuentros participativos, interpeladores o interactivos y abiertos. Así, dinámicas presenciales de clase mutaban y se ponían en movimiento en sus hogares, por ejemplo: documentar pedagógicamente situaciones de su hogar, rebuscar entre sus objetos de infancia, hacer búsquedas en Google para comprobar cuál era la imagen social (inconsciente colectivo) de la Educación Infantil o, como en este ejemplo, realizaron dibujos que compartieron en foros comunes:

Me ha gustado mucho iniciar la clase haciendo una de las cosas que más me gustan y es dibujar. Pero no dibujar algo cualquiera, sino dibujar al hombre o la mujer "ideal". Como ya he reflejado en el foro habilitado para ello, pienso que el hombre o mujer ideal no existen y cada uno debe sentirse bien y reconocido con lo que quiere ser. [Irene | Diario | 28.04.2020].

Por último y en relación al cuidado de los materiales que hacemos llegar a las alumnas, ya en la experiencia anterior al confinamiento apostábamos por un sello estético que se diferenciara las estéticas habituales de la Educación Infantil.

En el paso a la virtualidad total, decidimos hacer énfasis en este eje por la necesidad generar un "contagio" emocional (Giudici, Krechevsky y Rinaldi, 2016) que facilitara la apertura de nuevos horizontes ahora que ya no contábamos con nuestra presencia física. Así fue que consideramos importante cuidar no solo el contenido sino también la visualidad de las presentaciones que ofrecíamos, acompañándolas además por otros materiales también cuidados como anécdotas e historias que ofrecieran nuevas oportunidades de vincularlas con la realidad. Materiales que ayudaran a contextualizar sus aprendizajes y a generar un compromiso con su profesión y, por supuesto, con las infancias:

Reconstruyendo el conocimiento práctico en confinamiento. Una experiencia de enseñanza en la formación inicial de docentes. Soto, Maldonado-Ruiz, Márquez-Román \& Peña. 
Como he dicho antes, me ha gustado bastante el tema de aprendizajes basado en proyectos. [...] Dos cosas que destacaría de manera positiva es el vídeo del profesor, ya que lo que ha contado me ha parecido bastante motivante y la parte de después de la presentación ya que ha sido como una reflexión, pero un poco más personal, en la que he podido contar más cosas sobre mí [Paloma | Diario | 13.05.2020].

\section{La importancia de esencializar el curriculum}

Había que reducir contenido y ganar espacios para la tutorización. Este curriculum esencial afecta y se ve afectado y diluido por todos los ejes anteriores, como por ejemplo en el debate que acabamos de exponer sobre el diseño de los materiales curriculares o la vivencia temporal. Debíamos seleccionar un abanico sustancial y contrastado de conceptos y debates teóricos que dejara tiempo para el encuentro y la relación con la experiencia de las estudiantes con el filtro de las TIC.

\section{El dilema de la experiencia situada. La teoría y la práctica, una relación ineludible}

¿Cómo facilitar la reconstrucción del conocimiento práctico en confinamiento? ¿Cómo generar espacios de relación teórico-prácticos? ¿Cómo generar un contexto práctico con la escuela infantil en el escenario virtual?

Uno de los dilemas más profundos para el equipo fue el reto de repensar el habitus pedagógico que habíamos diseñado para promover la reconstrucción de su conocimiento práctico en la presencialidad, buscando la posibilidad de situar su reflexión teórica en contextos de sentido también en la virtualidad. Como fuente de inspiración, observamos cómo las maestras y maestros de infantil estaban atendiendo y acompañando a su alumnos y alumnas en el confinamiento, es decir analizar la "sabiduría práctica" (Kinsella y Pitman, 2012), o lo que entendemos por pensamiento práctico, de aquellos docentes con los que habitualmente colaborábamos y que participan en interesantes proyectos educativos. Ellas también estaban en sus casas y desde ahí, tenían que enfrentarse a la incertidumbre del encuentro con las infancias. Así es como decidimos apostar por diseñar creativamente espacios y momentos en los que las estudiantes se pudieran "acercar", de manera metafórica y real con docentes que día a día estaban desarrollando su práctica cotidiana.

\section{Cuentacuentos como encuentros con otras y otros}

Cuando la formación era presencial, abríamos cada una de las sesiones con una dinámica diferente: lectura de un cuento, visionado de un vídeo, audición de una canción, etc. Una manera de conectar y crear una plataforma emocional (Aguado Romo, 2015), con ellas y ellos y con lo que supone ser docente de infantil. La virtualidad no podía interrumpir este espacio de relaciones y, para seguir alimentando esa conexión emocional y motivacional, organizamos una red de cuentacuentos, donde maestros o maestras, autores, madres, estudiantes, incluso algún niño o niña les daban los buenos días con un mensaje cargado de optimismo y esperanza a través de un canal de Youtube titulado "Aprendiendo con las infancias" [Fig. 6]. Desde aquí debemos reconocer y agradecer la inmediata e intensa participación de las personas a las que invitamos a participar, un total de setenta y cuatro historias, y un arduo trabajo de montaje extra que compensó nuestro esfuerzo al percibir la acogida y el impacto que tenía en ellas:

Reconstruyendo el conocimiento práctico en confinamiento. Una experiencia de enseñanza en la formación inicial de docentes. Soto, Maldonado-Ruiz, Márquez-Román \& Peña. 


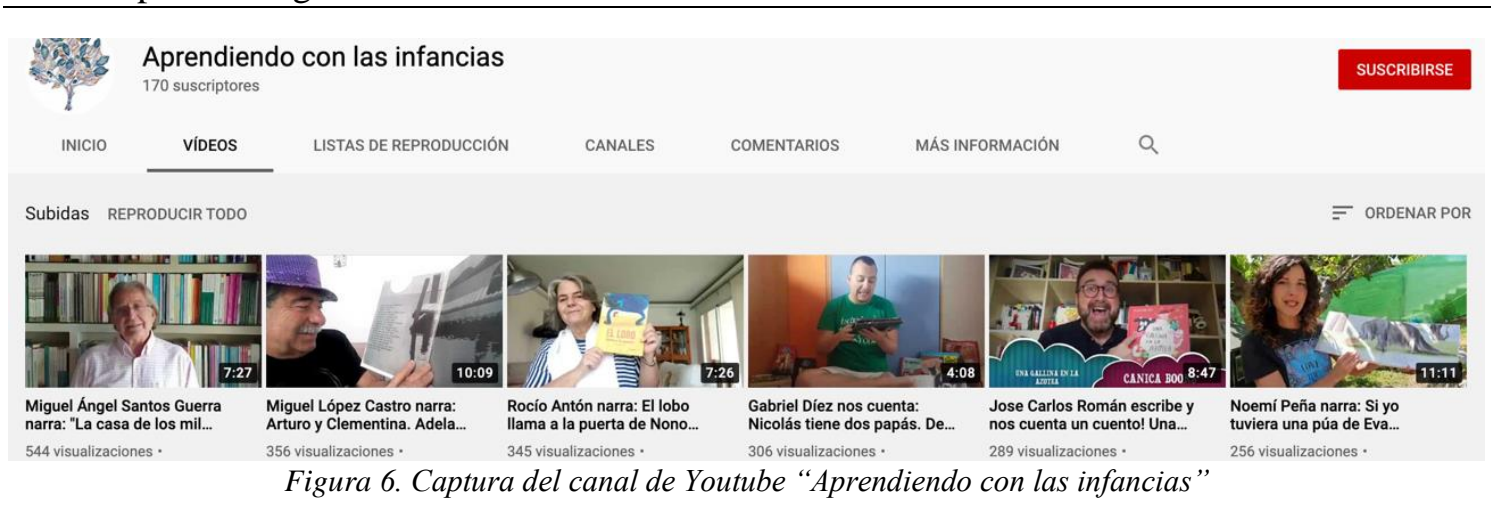

La verdad es que cada día espero ilusionada por ver qué cuento es el que toca ese día, y algo que me resulta muy productivo, es poder visionar a personas totalmente distintas realizando la lectura de cuentos infantiles, porque a la vez que me están enseñando más acerca de cómo leer un cuento infantil, a su vez se ve reflejado las distintas formas que tiene de hacerlo, unos enseñan los cuentos mientras lo relatan, otros prefieren no hacerlo, [...] y gracias a todos y cada uno de ellos sé que voy a llegar a conseguir mi propia identidad para en un futuro poder leerles los libros a los infantes. [María | Diario | 23.04.2020].

\section{Los retos semanales}

En el contexto virtual seguimos promoviendo los encuentros desde y con la teoría habituales como modos de "entendimiento encarnado" (Pérez Gómez, 2017) que las vinculara biográfica y emocionalmente con cuestionamientos pedagógicos relevantes y actuales como las preguntas individuales y colectivas y los nuevos materiales diseñados para las sesiones teóricas. Sin embargo, tomamos conciencia que necesitábamos ampliar las vías de reflexión y conexión de la teoría con sus experiencias de manera más integrada, conectada y compleja por lo que diseñamos lo que denominamos retos semanales.

Este momento semanal de reflexión, invitaba a las estudiantes a volver a visitar sus portafolios, generando procesos metacognitivos que les ayudaran a detectar sus propios aprendizajes. Un proceso de reflexión tutorizado, donde se rescataban aquellos temas o conceptos que podrían suponer oportunidades de "re-lectura" de lo escrito, incorporando nuevas preguntas o provocaciones (vídeo, fotografía, artículos, etc.) que facilitaran la reflexión sobre su propio proceso de aprendizaje. A veces, se incorporaban debates actuales en las escuelas o lo educativo. Para responder a éstas, debían volver tras sus pasos, recuperando de su diario aquellos momentos donde habían reflexionado sobre esas cuestiones, algo que sorprendió a un número amplio de estudiantes al darse cuenta la evolución en sus teorías proclamadas:

El proceso de volver a leerme me ha servido para, además de volver a recordar conceptos, saber si la definición de éstos ha cambiado. Además, he podido ver la equivocación que cometimos tanto mis compañeras como yo en establecer los vídeos como educativos sin ni siquiera pensar en la definición de ésta. [Helena | Diario | 30.04.2020]

\section{Una Lesson Study inconclusa}

Como hemos mencionado anteriormente, desde el curso 2015/2016, la Lesson Study se incorporó en nuestro proyecto. Sin embargo, el paso a la docencia online zarandeó una estrategia que necesariamente requería el vínculo con un contexto de práctica real. ¿Cómo desarrollar una lección experimental en Educación Infantil a distancia?

Reconstruyendo el conocimiento práctico en confinamiento. Una experiencia de enseñanza en la formación inicial de docentes. Soto, Maldonado-Ruiz, Márquez-Román \& Peña. 
Qué duda cabe que todas las fases iniciales de diseño de la lección (fases 1 y 2) que facilitaban el proceso de teorizar la práctica, podían desarrollarse en el formato virtual con reuniones semanales a través de videoconferencia con cada uno de los grupos de trabajo, poniendo en cuestión el diseño que estaban realizando. Estos momentos de encuentro nos servían para establecer debates con ellas que, además de ofrecer una imagen del contenido de las tres asignaturas de manera interconectada (la ecologización de las disciplinas de Morin, 2001), también situaban la reflexión sobre el curriculum en objetos y disposiciones concretas. Nuestra función tutorial está marcada también por una imagen de identidad profesional como "proceso constante de búsqueda" (Arndt et al., 2018), la tarea debía convertirse en una experiencia de diseño emergente donde la Teoría se convierta en una verdadera herramienta de comprensión y de acción:

Aplaudo que se nos plantearan conceptos que de verdad nos serán útiles en nuestro trabajo y que se reconociera su importancia, como la colaboración docente. Y que nosotros y nosotras hayamos podido comprobarlo a través de vuestro ejemplo. [Comentario anónimo | Evaluación final].

Sin embargo, la dificultad estaba en cómo recrear la fase de desarrollo de la lección experimental en la virtualidad con niños y niñas de 3, 4 o 5 años, es decir cómo generar contextos de experimentación de la teoría que estaban diseñando y que finalmente tuvimos que aplazar para otra oportunidad en otro curso y contexto.

Como aspectos a mejorar, necesito ver la práctica, pero entiendo que con la Lesson Study hubiese sido posible y con lo de la Covid-19 no se ha podido llevar a cabo. [Comentario anónimo | Evaluación final].

Sin embargo, seguíamos buscando ese "clima de experimentación" real (Argyris, 1999) y pensábamos que el contexto de complejidad que vivíamos suponía una oportunidad para posicionarse moralmente como profesionales de la educación y conectar la formación inicial con lo que estaba pasando con las escuelas y, en consecuencia, con los niños y niñas que la habitan. Necesitábamos recuperar el "tercer espacio", un lugar compartido, físico y virtual para el diálogo, la reflexión, la conexión y el aprendizaje (Damjanovic et al., 2017, p. 33) y de relación con las escuelas.

Y así fue como nos pusimos en contacto con las docentes que iban a traer a sus niños y niñas a la Facultad para hacerles una nueva propuesta:

\section{Acercarse a las infancias en tiempos de confinamiento}

La gran cantidad de recursos que en aquellos meses y desde múltiples lugares se compartían en red -y que analizábamos con nuestras estudiantes- nos ofrecía un campo privilegiado para analizar y diseñar una propuesta pedagógica en formato vídeo que pudiéramos compartir con las familias y sus hijos e hijas a través de la red de maestras que habíamos creado y con el resto de la comunidad a través del canal de Youtube descrito.

Otra cosa que realmente nos ha llamado bastante la atención y por lo tanto nos ha encantado, es el factor sorpresa que la profesora nos ha propuesto realizar, y que por lo tanto estamos encantadas, y podemos ser de gran ayuda a los docentes de infantil realizando propuestas que los padres puedan hacer en casa con sus hijos e hijas, y que de esta manera aprendan divirtiéndose [María | Diario | 15.04.2020].

Reconstruyendo el conocimiento práctico en confinamiento. Una experiencia de enseñanza en la formación inicial de docentes. Soto, Maldonado-Ruiz, Márquez-Román \& Peña. 
Tras esto, las familias enviaron vídeos a nuestras estudiantes de sus niños y niñas en pleno proceso de creación, y el último día de clase visionamos estas respuestas en un clima de emoción profunda y recogimiento:

Personalmente yo me emocioné mucho cuando vi ese vídeo que contenía fotos y vídeos de los niños/as realizando las distintas propuestas que habíamos pensado para ellos/as durante el confinamiento. Cuando vi las caras de los niños/as realizando cada una de esas propuestas me sentí muy feliz. En concreto, cuando en el vídeo salió la propuesta de mi grupo [...], me llevó a reflexionar bastante, ya que vi todo lo que podíamos despertar en los niños/as con muy poquito. [Loreto | Diario | 04.06.2020].

Pese a lo impactante que resultó esta experiencia para las estudiantes, podría haber sido potencialmente más educativa para ellas si hubiéramos mostrado el feedback recibido con anterioridad, éste podía haber traspasado la experiencia emotiva para convertirse en un momento de reflexión después de la "acción" (Schön, 1992). Podrían haber identificado focos de mejora en los recursos diseñados, incorporando en gran medida la filosofía de trabajo propuesta desde la tradición de las Lesson Studies y que no pudimos desarrollar de forma completa.

\section{La tutoría de la experiencia: el acompañamiento emocional y la actitud de escucha}

La situación sobrevenida provocada por la pandemia generó la necesidad urgente de repensar nuestro modelo de tutorización y de acompañamiento en el formato virtual, sobre todo una adaptación más centrada en la comprensión del contexto social que estábamos viviendo que en una modificación de los principios que los vertebraban. Así fue como el tema de las emociones en circunstancias de confinamiento centraron la mayor parte de nuestras inquietudes y dilemas: ¿cómo realizar el acompañamiento de los grupos de manera online y encontrar el equilibrio entre la frialdad de los medios técnicos y la relativa "invasión" que supone meternos en sus casas a través de las videollamadas? ¿Cómo seguir estimulando la pasión por el saber en un marco de conocimiento tan inestable y confuso? ¿Cómo cuidar la relación en este nuevo contexto?

Como docentes universitarios, y siguiendo a Pérez Gómez (2020), pensamos que el reto principal de la educación y, por ende, de la enseñanza (en nuestro caso la universitaria) está en " $[\ldots]$ asumir de manera intencional y sistemática la responsabilidad de provocar, promover, orientar y ayudar a cada estudiante en la reconstrucción consciente de sus modos habituales de pensar, sentir y actuar" (p.14), es decir, promover la singular construcción de su identidad como docente. Dicho esto, la cristalización de este planteamiento tutorial en la enseñanza virtual universitaria quedó marcada por dos ejes fundamentales: el acompañamiento y sostén emocional y la actitud de escucha abierta, comprensiva y estimulante.

\section{El acompañamiento emocional}

Tutor: ¿Cómo están los ánimos esta semana? Estoy especialmente interesado en encontrarme con vosotras [...].

A: Yo mal, la verdad.

Tutor: ¿Por qué?

A: Porque soy una rallada de la vida, me estoy rallando. Me estoy preocupando. No tiene nada que ver con los estudios, pero me estoy preocupando.

Reconstruyendo el conocimiento práctico en confinamiento. Una experiencia de enseñanza en la formación inicial de docentes. Soto, Maldonado-Ruiz, Márquez-Román \& Peña. 
Tutor: Bueno, si te podemos echar una mano quiero que sepas que puedes contar con nosotros.

\section{A: Es que si os lo cuento voy a empezar a llorar y tampoco quiero...}

Tutor: Lo que te apetezca. Llorar no es problema, pero si te apetece... (después de que la alumna detalle su problema el tutor sigue acompañando).

Tutor: Pero mi invitación es a que busquéis gente con la que explotéis. Pero no os sintáis mal por sentiros mal, sentíos mal y ya está. Porque estáis viviendo momentos de saturación y estrés y no puede ser que no os podáis permitir sentiros mal. [Grupo E | Seminario virtual | 20.05.2020]

Hemos querido comenzar este subapartado con el fragmento de una de las reuniones de tutorización de pequeños grupos para evidenciar el grado de acompañamiento que llevamos a cabo en estos encuentros. Por lo general, antes de hablar de la temática del día animábamos a los estudiantes a expresarse emocionalmente. Este ejercicio, aparte de permitir la autorrevisión personal también facilita la empatía grupal y la creación de un clima de confianza y cercanía. Considerando el contexto coyuntural que estábamos atravesando, estos minutos de "desahogo" eran cruciales y nos permitían disponernos a las cuestiones teóricas de una manera más abierta y conectada con el momento en el que se encontraban.

Este acompañamiento emocional sutil y cercano también estaba presente en los feedbacks que hacíamos en los portafolios virtuales. Así, esta compleja función la in-corp-oramos desde tres principios claves que Korthagen (2010) define como: ayudar a las estudiantes a tomar conciencia de sus aprendizajes; ayudarlas a encontrar experiencias útiles de las que inspirarse; y ayudarlas a reflexionar y analizar en detalle estas experiencias.

¡Hola Rebeca! ¿Cómo estás? ¿Cómo llevas el confinamiento? Espero que tú y los tuyos lo estéis llevando de la mejor manera posible ¡Cuántos temas interesantes sobre los que profundizar y dialogar! En primer lugar, quisiera darte las gracias por compartir un trocito de ti conmigo. Estoy segura de que esta experiencia más cercana será valiosa para ambas y me gustaría que supieras que el objetivo de todo lo que te escribiré de ahora en adelante es para tu crecimiento personal y para que te sientas acompañada en este proceso de formación como docente. Me ha hecho mucha ilusión saber que has comenzado la andadura del voluntariado en el hospital. ¿Sigues con ello a pesar de las restricciones? Se me ocurre que podrías ir conectando lo que vamos viendo con lo que vives en esa planta lúdico-educativa del hospital. Yo en mi etapa de estudiante intenté hacer ese mismo voluntariado, pero al vivir tan lejos de Málaga me lo hacía muy difícil... [Tutora | Feedback en diario de Rebeca | 18.03.2020]

Este acompañamiento es valorado positivamente por el alumnado participante cuando en sus diarios, van compartiendo sus reflexiones, razonamientos y emociones en relación con la experiencia:

También hemos podido transmitirle a la profesora cómo nos sentimos y cómo percibimos lo que estamos trabajando en este momento. Desde una opinión muy personal creo que las tutorías así nos enriquecen mucho más que las que solamente hablamos sobre los contenidos de los trabajos planteados, esto nos permite conocernos más y por ello adentrarnos más en las ideas del otro y en lo que la otra persona quiere transmitirnos, pues a veces creo que es complicado que tu mensaje

Reconstruyendo el conocimiento práctico en confinamiento. Una experiencia de enseñanza en la formación inicial de docentes. Soto, Maldonado-Ruiz, Márquez-Román \& Peña. 
llegue exactamente igual a como tú lo tienes estructurado a 60 o más alumnos y alumnas. [Carmina | Diario | 20.05.2020].

Sin embargo, y como ya era un lugar común en los intercambios presenciales, algunas temáticas removían creencias vinculadas afectiva e ideológicamente con su experiencia y bagaje personal, provocando incomodidades o fricciones que no sabíamos muy bien cómo gestionar en el medio virtual, es decir, cómo trasladar la presencia del cuerpo, del gesto, en esos momentos para expresar un feedback delicado que les ayudara a transitar por terrenos hostiles.

Estos momentos de contraste intersubjetivo con la teoría ayudaban a construir una percepción de comunidad profesional que "se ve facilitada por el encuentro y el intercambio en un plano horizontal de subjetividades con experiencias biográficas diferentes que se enriquecen de la colaboración y el intercambio (Martínez Bonafé, 2010, p. 109). El contexto del confinamiento implicaba además una fuerte carga emocional que debíamos tener en cuenta.: [...] me he sentido cómoda y con la libertad de poder expresarme. [Helena | Diario | 07.05.2020]

\section{La actitud de escucha}

La dimensión de la escucha se convierte también en uno de los ejes fundamentales de este proceso de tutorización en tiempos de confinamiento. Según Motta (2017) la "actitud de escucha" requiere de un conjunto de procesos de reconocimiento, percepción e interpretación de la relevancia de lo que se dice en referencia a la conversación o tópico del que se está hablando. Un proceso complejo y acompañado de un fuerte compromiso ético por parte de quien la realiza:

Escuchar implica estar abierto/a a ser afectado/a. Se trata de estar abierto/a [...] a la diferencia en toda su multiplicidad a medida que emerge en cada momento entre uno/a mismo/a y otro/a. Escuchar es no estar condicionado/a por lo que ya sabes. Es la vida como movimiento (Davies, 2014, p. 1)

Siguiendo con Motta (2017) "en el contexto del aula, escuchar hace referencia a una disposición de los sujetos de la conversación pedagógica (maestro-estudiante y estudiante-estudiante) para poner en circulación su sentir, su pensar y su actuar en beneficio de su propio desarrollo humano" (p. 155). Es así como la institución educativa se convierte en un auténtico escenario para el desarrollo de la pedagogía de la escucha, y para la suspensión de la vida rutinaria que permite un posicionamiento más crítico.

Como equipo docente, hemos intentado que cada uno de los momentos de relación vividos en esta experiencia hayan estado marcados por la dignificación de esta actitud de escucha tan necesaria en los contextos educativos y a la vez tan intangible. El alumnado es consciente de esta actitud, considerándola como uno de los principios más significativos y valiosos de la experiencia:

Desde el principio de las clases habéis contado con mis opiniones, me habéis dado la oportunidad de expresarme y habéis tenido mis opiniones en cuenta. Habéis conseguido en cada debate que participara y me involucrara... Incluso ahora, en mi vida personal, llevo por delante los valores que he adquirido en tan solo 4 meses. Yo no soy la misma persona y os estaré eternamente agradecida. [Hanna | Diario | 05.06.2020].

Reconstruyendo el conocimiento práctico en confinamiento. Una experiencia de enseñanza en la formación inicial de docentes. Soto, Maldonado-Ruiz, Márquez-Román \& Peña. 
Las tutorías eran geniales pues, aunque nos quejábamos mucho, sentía que siempre podíamos hablar de cualquier cosa y eso precisamente es lo que hace que me sintiera como en casa. [Carolina | Email a la tutora | 04.06.2020].

También nos parece importante destacar como fortaleza del contexto online para la escucha y la tutorización, la posibilidad de atención plena que este medio aporta. Generalmente y con los grupos numerosos que manejamos en la enseñanza del profesorado el nivel de ruido y dispersión que se produce en los intercambios emergentes y cotidianos del aula impiden una escucha sosegada y atenta.

Por último, es este ejercicio de escucha que nos cuestiona e interroga el que nos ha permitido vivir este proyecto educativo como una experiencia en constante transformación. A raíz de nuestros encuentros con ellas, tanto a nivel oral como escrito, hemos ido ajustándonos a una realidad nueva para todas y todos y donde el alumnado se sentía actor principal del proceso vivido.

Sois de esos profesores en los que pienso como quiero ser yo como futura docente y os tengo de ejemplo, que nos escucháis, nos hacéis sentir importantes, valoradas $y$ de los que se preocupan por nuestros sentimientos. [Comentario anónimo | Evaluación final].

\section{La coordinación docente como sostén. Una conexión permanente}

A pesar de que la coordinación ha sido uno de los ejes sustanciales del proyecto en tiempos de presencialidad, en el confinamiento se ha convertido en uno de los sostenes fundamentales para atender al escenario tan incierto en el que nos encontrábamos y el impacto emocional que esta complejidad nos generaba. Así, este continuo diálogo no sólo facilitaba, como hemos comentado anteriormente, la emergencia de posibilidades de diseño de tiempos y espacios flexibles, sino que ofrecía una imagen "reivindicativa y comprometida" para "salvar" la situación en la que estábamos inmersos:

En muchas ocasiones creo que he aprendido más de vosotros como maestros que del tema que tratábamos en las presentaciones [Comentario anónimo|Evaluación final].

En este marco compartido de principios pedagógicos, como ya avanzábamos, contábamos tanto con docentes noveles que aún se encuentran en su etapa de formación predoctoral como docentes experimentadas, algunas de las cuales incluso fueron autoras de la génesis de este proyecto coordinado hace ya varios cursos. Esto, que bien podría ser sólo un apunte descriptivo, facilita que la experiencia de coordinación también se convierta en sí misma en una plataforma de formación para docentes noveles donde, a través del diálogo continuo, se construye cooperativamente una mirada diferenciada y peculiar sobre lo que significa aprender a enseñar a ser docentes.

A nivel organizativo, la intensidad de esta experiencia educativa y la diferencia de horas asignadas de docencia dentro del marco de las tres citadas asignaturas, hacían emerger (con mayor fuerza en esta etapa de confinamiento) un concepto vertebrador de la coordinación: la sostenibilidad. La ilusión y el compromiso, así como el resto de nuestros principios pedagógicos deben sostener una práctica docente equilibrada. Sin embargo, y desde las cargas docentes que cada uno y cada una tenía en el proyecto no dejamos de desarrollar una coordinación intensa, tanto en las decisiones macro del proyecto como en el día a día del aula y de la relación que se establecía con las estudiantes. Una coordinación que nos ha supuesto una red de seguridad y acompañamiento emocional fundamental para afrontar el incierto escenario del confinamiento.

Reconstruyendo el conocimiento práctico en confinamiento. Una experiencia de enseñanza en la formación inicial de docentes. Soto, Maldonado-Ruiz, Márquez-Román \& Peña. 
Cuidar el bienestar del equipo docente ha sido importante para la experiencia. Un espacio que, además de funcionar de sostén nos permitía conocernos de manera más profunda y sincera, facilitando el crecimiento pedagógico de nuestras prácticas por la confianza con la que podíamos compartir nuestras inquietudes y reflexiones constructivas.

Otro de los ejes para la coordinación eficaz podría ser la horizontalidad que había en nuestra relación. Un elemento que contrasta con lo que se podía esperar por la diversidad de trayectorias de los miembros del equipo que anteriormente hemos mencionado. En nuestros debates y discusiones procurábamos llegar a consenso, argumentando, debatiendo entre ventajas e inconvenientes, dando consejos y apoyándonos los unos a los otros.

Profesora 1: ¿Cómo van las dudas con las alumnas? ¿Os entran muchos correos? Yo ya he tenido unos pocos...

Profesora 2: Algunos. Me acaba de entrar duda con objetivos y contenidos. Ya no sé cómo explicarlo... ¿Cómo lo explicáis vosotros para que se entienda la diferencia?

Profesora 1: Yo les digo que los objetivos son las competencias, y que los contenidos son el instrumento para poder llevar a cabo esas competencias. Los objetivos son el para qué y los contenidos el qué. Entonces si el objetivo es "vivir y convivir en grupos humanos cada vez más heterogéneos”, los contenidos son la escucha, la comunicación, el respeto, el valor de la diferencia, etc.

Profesora 2: Así tal cual lo he explicado mil veces. Aun así, les cuesta.

Profesor: Yo creo que para esa duda ya es mejor que te veas en tutoría, porque si no lo tiene claro después de tres mil debates, en un correo escrito tampoco le va a quedar claro [Equipo docente | Chat de coordinación | 01.06.2020].

Sin embargo, esta etapa de confinamiento también acentuó la interdisciplinariedad en el equipo. Ahora el/la tutor/a acompaña, debate, cuestiona y sugiere a las estudiantes con respecto al contenido de las tres asignaturas. Eso exigía estar al día sobre los contenidos teóricos de cada sesión (e incluso de los recursos ofrecidos), gestionando así cooperativamente las posibles dudas que le iban surgiendo al alumnado y por tanto intensificando la coordinación, en algunos momentos estresante (sobre todo para los docentes noveles), aunque fue valorado muy positivamente por el alumnado.

Desde el minuto uno de la presentación de las tres asignaturas me di cuenta de que la innovación educativa no es algo que vaya de boca en boca, sino que realmente se lleva a la práctica de una forma claramente observable. [...] Tenía esa idea de que la innovación no existe porque he vivido muchas situaciones en las que se ha denominado con ese nombre a la tradición disfrazada, pero, afortunadamente, he podido destruir esa concepción desde que he visto a los tres profesores remando con un único objetivo [Elisa | Diario | 23.02.2020].

\section{Conclusiones}

Tras la narración de esta experiencia formativa durante el "confinamiento", queríamos compartir algunas "lecciones aprendidas" desde una mirada honesta y situacional, como un punto y seguido que nos ayude a seguir pensando sobre el sentido que, tanto en la virtualidad como en la presencialidad, la formación inicial de maestras y maestros tiene para nuestro equipo. Así, si nuestro propósito fundamental era estimular la reconstrucción

Reconstruyendo el conocimiento práctico en confinamiento. Una experiencia de enseñanza en la formación inicial de docentes. Soto, Maldonado-Ruiz, Márquez-Román \& Peña. 
del conocimiento práctico de nuestros estudiantes, las experiencias vividas y las propuestas desarrolladas, nos ayudan a entender ciertas implicaciones y complicaciones que la enseñanza virtual (en confinamiento) nos ha mostrado:

- La traslación mecánica del curriculum y de las formas de enseñanza presencial no funciona. Es imprescindible una revisión del curriculum y de la metodología didáctica para adaptarse a las exigencias pedagógicas de la doble singularidad que hemos vivido: la enseñanza online y la situación específica de confinamiento.

- La formación inicial de los docentes requiere contextos relevantes y sugerentes para desarrollar estos programas teórico-prácticos (Hu et al., 2019) donde la actividad, la experiencia y la cooperación sean el eje para aprender a analizar, diseñar, experimentar y evaluar propuestas pedagógicas adecuadas en procesos extensos y cíclicos de investigación acción cooperativa (Barbour, 2019). Durante esta experiencia de enseñanza virtual, sin embargo, se han hecho patentes las dificultades para emular en estas condiciones un contexto real y situado de enseñanza para la Educación Infantil donde se pueda vincular la teoría y la práctica, y que nuestras estudiantes puedan ponerse en contacto directo con los niños y niñas de infantil, es decir de experimentar la teoría. Esto nos enfrenta a un dilema real: ¿es posible generar un proceso de enseñanza y aprendizaje online para aprender a ser maestra/o de Educación Infantil? Y, por ende, $i$ es posible reconstruir el conocimiento práctico de las futuras docente de infantil con una enseñanza 100\% virtual? En nuestra opinión no es posible por la naturaleza y características intrínsecas de la etapa. Si la docencia online en tiempos de confinamiento ha sido mayoritariamente sostenida por las familias, en la formación inicial online es imposible generar procesos y provocaciones reales donde como docente tengas una relación directa con las infancias marcada por la incertidumbre y la sucesión de respuestas intuitivas que ésta exige.

- Sin embargo, sí tenemos evidencias de las posibilidades que los principios y las tareas y propuestas didácticas desarrolladas, en definitiva, el habitus pedagógico de nuestro proyecto, han conseguido reflejarse, al menos, en las teorías declaradas de las estudiantes que han participado en el proceso. Se ha mostrado tanto la potencialidad de la estructura reflexiva sostenida en los bloques teórico-prácticos, como las diferentes iniciativas didácticas propuestas en las primeras fases de la Lesson Study, así como la tutorización cercana y emocional, el portafolios digital y las tareas vinculadas con las escuelas que han supuesto un entramado privilegiado para teorizar la práctica y por tanto descubrir, al menos, la inestable solidez de sus creencias previas.

En este sentido, hemos podido evidenciar la importancia de diseñar propuestas desde los principios pedagógicos de procedimiento y no desde los contenidos o herramientas digitales en esta etapa incierta. Es necesario seguir ampliando y explorando el debate sobre las virtualidades pedagógicas de las múltiples y diferentes herramientas que se han puesto de forma compulsiva a disposición del profesorado. De hecho, a lo largo de cuatro meses en nuestro proyecto hemos utilizado un amplio repertorio: Skype, Google Hangouts, Campus virtual (Moodle), Google Meet, Mentimeter, Youtube, BigBlueButton (Seminario virtual de la UMA), Portafolio UMA (Mahara), Whatsapp e Instagram. Esto unido a todas aquellas que hemos probado internamente y que no llegaron al alumnado: Telegram, Microsoft Teams y un largo etcétera. Nuestra experiencia ha evidenciado de nuevo que menos es más, y que necesitamos diseñar sin perder la coherencia pedagógica con nuestros principios utilizando aquellos recursos que mejor la acompañen.

Reconstruyendo el conocimiento práctico en confinamiento. Una experiencia de enseñanza en la formación inicial de docentes. Soto, Maldonado-Ruiz, Márquez-Román \& Peña. 
Además de todo lo mencionado, el análisis realizado ha permitido trazar un camino que, ha intentado converger y sustentarse en cuatro pilares básicos: el desarrollo del pensamiento práctico a través de la necesaria relación teoría-práctica; un curriculum esencial e interdisciplinar; la tutorización y relevancia de las emociones; y la coordinación docente. Una experiencia caracterizada por probaturas, tensiones, retos, errores, saturación, dureza del acompañamiento emocional, velocidad para tomar decisiones. Un camino, también, lleno de miradas y sonrisas cómplices tras una pantalla; de aprendizajes y crecimiento profesional y personal.

A pesar de la valoración positiva que hace la mayoría de las estudiantes sobre la experiencia, seguimos planteando interrogantes que debemos seguir pensando para la virtualidad: ¿cómo diversificar los espacios para que las estudiantes no sientan que están todo el día frente a una pantalla? ${ }^{10}$, ¿cómo generar contextos de realidad en la Educación Infantil, donde se puedan poner en juego como maestras y maestros?

Finalmente, podemos afirmar que el escenario virtual se ha convertido en un espacio cercano, donde cabe la sonrisa y no la mascarilla, y donde las estudiantes se pueden sentir acompañadas y en relación. Un espacio personal que puede trascender la cultura academicista que caracteriza con tanta frecuencia la formación inicial de docentes. La cooperación, tanto entre los estudiantes como entre los docentes que los forman es, no solo una estrategia que facilita el aprendizaje relevante de las competencias profesionales de los futuros docentes para situaciones extraordinarias, sino que la cooperación también ofrece, las condiciones necesarias de un clima profesional para enfrentar la incertidumbre de procesos tan complejos y diversos como inciertos, al tener que responder a las condiciones socioculturales y tecnológicas tan distintas de cada uno de los aprendices.

En definitiva, lo que este trabajo invita a pensar es que construir un habitus pedagógico en el confinamiento, supone un proceso con múltiples complejidades, pero, al mismo tiempo, una oportunidad para convivir en un espacio (físico, virtual y metafórico) en donde todos/as aquellos/as que lo habitamos podemos vivir nuestras metamorfosis profesionales desde la más profunda honestidad, y como decía una evidencia compartida anteriormente con gran clarividencia, sintiéndonos en casa.

Presentación del artículo: 15 de octubre de 2020

Fecha de aprobación: 9 de noviembre de 2020 Fecha de publicación: 08 de enero de 2021

Soto, E., Maldonado-Ruiz, G., Márquez-Román, A. y Peña, N. (2021). Reconstruyendo el conocimiento práctico en confinamiento. Una experiencia de enseñanza en la formación inicial de docentes. RED. Revista de Educación a Distancia, 21(65). https://doi.org/10.6018/red.450621

\section{Financiación}

Este trabajo forma parte de una investigación realizada por el grupo HUM311 (Repensar la Educación) en el marco del proyecto EDU2017-86082-P: "Lesson Studies. Escuela y universidad: Investigando la reconstrucción del conocimiento práctico en la formación

\footnotetext{
${ }^{10}$ Existe la necesidad imperiosa de crear y repensar los espacios y tiempos educativos en la virtualidad estableciendo límites en los tiempos de exposición a la pantalla en virtud de las diferentes edades de los aprendices (Duckworth, 2020).

Reconstruyendo el conocimiento práctico en confinamiento. Una experiencia de enseñanza en la formación inicial de docentes. Soto, Maldonado-Ruiz, Márquez-Román \& Peña.
} 
inicial del profesorado". Este proyecto está financiado por el Plan Nacional de Investigación del Gobierno de España.

\section{Referencias bibliográficas}

Aguado Romo, R. (baum2015). Es emocionante saber emocionarse. EOS.

Andersen, C.L. y West, R.E. (2020). Improving mentoring in higher education in undergraduate education and exploring implications for online learning. RED. Revista de Educación a Distancia, 64(20), 1-25. https://doi.org/10.6018/red.408671

Argyris, C. (1999). Conocimiento para la acción. Granica.

Atkinson, T. (2002). Aprender a enseñar: habilidades intuitivas y objetividad razonada. En G. Claxton y T. Atkinson (Eds.), El profesor intuitivo (pp. 95-112). Octaedro.

Alconada Mon, H. (25 de julio de 2020). Coronavirus. Jacques Attali: La humanidad aún no comprendió la profundidad de la crisis que se avecina y el costo de la resurrección. La nación. https://www.lanacion.com.ar/el-mundo/coronavirusjacques-attalila-humanidad-aun-no-comprendio-nid2404532

Arndt, S., Urban, M., Murray, C., Smith, K., Swadener, B., y Ellegaard, T. (2018). Contesting early childhood professional identities: A cross-national discussion. Contemporary Issues in Early Childhood, 19(2), 97-116. https://doi.org/10.1177/1463949118768356

Bain, K. (2006). Lo que hacen los mejores profesores de universidad. Publicaciones de la Universidad de Valencia.

Barbour, M. K. (2019). The landscape of K-12 online learning: Examining the state of the field. En M. G. Moore y W. C. Diehl (Eds.), Handbook of distance education (4 ${ }^{\text {a }}$ ed., pp. 521-542). Routledge. https://doi.org/10.4324/9781315296135

Bauman, Z., y Leoncini Th. (2018). Generación líquida: Transformaciones en la 3.0. Paidós.

Beard, A. (2019). Otras formas de aprender: Qué funciona en educación y por qué. Plataforma Editorial.

Belmonte, Ó., Cuesta, C., Guadix, N., Hernández, A., y López de Turiso, A. (2020). COVID-19 Reimaginar la educación. Aprendizajes de la pandemia sobre los que construir un pacto por la educación. UNICEF España. https://www.unicef.es/sites/unicef.es/files/educa/unicef-educa-COVID-19Reimaginar-educacion-Pacto-Educativo.pdf

Bourdieu, P. (2008). Homo academicus. Siglo XXI.

Braidotti, R. (2015). Lo Posthumano. Gedisa.

Bronfenbrenner, U. (1999). Environments in developmental perspective: theoretical and operational models. En S.L. Friedman (Ed.), Measuring environment across the life span: emerging methods and concepts (pp. 3-38). American Psychological Association. https://doi.org/10.1037/10317-000

Reconstruyendo el conocimiento práctico en confinamiento. Una experiencia de enseñanza en la formación inicial de docentes. Soto, Maldonado-Ruiz, Márquez-Román \& Peña. 
Brown, G.T.L. (2017). What We Know We Don't Know about Teacher Education. En J. Clandinin y J. Husu (Eds.), The SAGE Handbook of Research on Teacher Education (vol. 2). Sage. http://dx.doi.org/10.4135/9781526402042

Brouwer, N., y Korthagen, F. (2005). Can teacher education make a difference? American Educational Research Journal, 42(1), 153224. https://doi.org/10.3102/00028312042001153

Clandinin, D. J., y Connelly, F. M. (1995). Teachers' professional knowledge landscapes. Teachers College Press

Clandinin, D. J., y Connelly, F. M. (2000). Narrative inquiry: Experience and story in qualitative research. Jossey-Bass.

Claxton, G. (2008). What is the Point of School? Rediscovering the Heart of Education. Oneworld Publications.

Contreras, J. (2010). Pedagogías de la experiencia y la experiencia de la pedagogía. En J. Contreras y N. Pérez de Lara (Eds.), Investigar la experiencia educativa (pp. 241269). Morata.

Corbera, E. (2015). El arte de desaprender. La esencia de la Bioneuroemoción. El grano de mostaza.

Cruz, J. (20 de abril de 2020). Carolin Emcke: La pandemia es una tentación autoritaria que invita a la represión. El País. https://elpais.com/cultura/2020-04-19/carolinemcke-esta-es-una-tentacion-autoritaria-que-invita-a-la-represion.html

Damjanovic, V., Quinn, S., Branson, S., Caldas, E., y Ledford, E. (2017). The use of Pedagogical Documentation Techniques to Create Focal Points in a SchoolUniversity Partnership in Early Childhood Education: Technologies that Create a «Third Space». School-University Partnerships, 10(3), 30-50. http://napds.org/wp-content/uploads/2017/07/The-use-of-PedagogicalDocumentation-Techniques-to-Create-Focal-Points-in-a-School-UniversityPartnership-in-Early-Childhood-Education_Technologies-that-.pdf

Darling-Hammond, L., y Oakes, M. (2019). Preparing Teachers for Deeper Learning. Harvard Education Press.

Davies, B. (2014). Listening to children: Being and becoming. Routledge. https://doi.org/10.4324/9781315770390

Duckworth, A. (27 de abril de 2020). What Teachers Should Worry About Right Now. Education

Week. http://blogs.edweek.org/edweek/ask_a_psychologist/2020/04/what_teachers_sho uld_worry_about_right_now.html

Elliott, J. (2012). Developing a science of teaching trough lesson study. International Journal for Lesson and Learning Studies, 1(2), 108-126. https://doi.org/10.1108/20468251211224163

Garret, L. (2020). The Coming Plague: Newly Emerging Diseases in a World Out of Balance. Penguin Books.

Gewertz, C. (2 de junio de 2020). How Technology, Coronavirus Will Change Teaching by 2025. Education Week. https://www.edweek.org/ew/articles/2020/06/03/howtechnology-coronavirus-will-change-teaching-by.html

Reconstruyendo el conocimiento práctico en confinamiento. Una experiencia de enseñanza en la formación inicial de docentes. Soto, Maldonado-Ruiz, Márquez-Román \& Peña. 
Giudici, C., Krechevsky, M., y Rinaldi, C. (2016). Haciendo visible el aprendizaje: Niños que aprenden individualmente y en grupo. Red Solare. Reggio Children Editore.

Gómez, R., y Ospina A. (2002). La lámpara sin genio: Usando telecentros para el desarrollo sin esperar milagros. Centro Internacional de Investigaciones para el Desarrollo.

Greenwood, D. J., y Levin, M. (2012). La reforma de las ciencias sociales y de las universidades a través de la investigación-acción. En N. Denzin y Y.S. Lincoln (Coords.), Manual de Investigación Cualitativa (vol. 1, pp. 117-154). Gedisa.

Grossman, P.L. (1990). The making of a teacher: Teacher Knowledge and Teacher Education. Teachers College Press.

Hagger, H. y Hazel, H. (2006). Learning teaching from teachers: Realising the potential of School-Based Teacher Education. Open University Press.

Hoyuelos, A. (2011). Introducción. Educación infantil: una canción a varias voces. Tarbiya, Revista de Investigación e Innovación Educativa, (42), 5-12. https://revistas.uam.es/tarbiya/article/view/258

Hu, Z., Petoukhov, S., Dychka, I., y He, M. (Eds.) (2019). Advances in Computer Science for Engineering and Education. Springer

Jackson, P.W. (1991). La vida en las aulas. Morata.

Jonnaert, P. (2006). Action et compétence, situation et problématisation. En M. Fabre y E. Vellas (Eds.), Situations de formation et problématisation (pp. 31-39). De Boerck. https://doi.org/10.3917/dbu.fabre.2006.01

Louv, R. (2008). Last Child in the Woods: Saving Our Children From Nature-Deficit Disorder. Atlantic Books.

Kinsella, E. A., y Pitman, A. (2012). Engaging phronesis in professional practice and education. En A. Pitman y E.A. Kinsella (Eds.), Phronesis as Professional Knowledge. Practical Wisdom in the Professions (pp. 1-12). Sense Publishers. https://doi.org/10.1007/978-94-6091-731-8

Klein, N. (2019). On Fire: The (Burning) Case for a Green New Deal. Simons \& Shuster.

Knight, D., Iliadi, K.G., Iliadi, N., Wilk, R., Hu, J., Krause, H.M., Taylor, P., Moran, M.F., y Boulianne, G.L. (2015). Distinct Regulation of Transmitter Release at the Drosophila NMJ by Different Isoforms of nemy. PLoS ONE, 10(8), e0132548. https://doi.org/10.1371/journal.pone.0132548

Korthagen, F. (2005). Introduction: Personal links that shape the identity of teacher educators. En G.F. Hoban (Ed.), The missing links in teacher education design: Developing a multi-linked conceptual framework (pp. 231-234). Springer. https://doi.org/10.1007/1-4020-3346-X

Korthagen, F. (2010). The relationship between theory and practice in teacher education. En P. Peterson, E. Baker, y B. McGaw (Eds.), International Encyclopedia of Education (vol. 7, pp. 669-675). Elsevier.

Korthagen, F., y Lagerwerf, B. (2008). Teacher's Professional Learning: How Does It Work? En F. Korthagen, J. Kessels, B. Koster, B. Lagerwerf, y T. Wubbels, Linking practice and theory. The Pedagogy of Realistic Teacher Education (pp.

Reconstruyendo el conocimiento práctico en confinamiento. Una experiencia de enseñanza en la formación inicial de docentes. Soto, Maldonado-Ruiz, Márquez-Román \& Peña. 
175-206). Routledge.

Korthagen, F., y Nuijten, E.E. (2018). Core reflection approach in teacher education. En J. Lampert (Ed.), Oxford research encyclopedia of education. Oxford University Press. https://doi.org/10.1093/acrefore/9780190264093.013.283

Leeferink, H., Koopman, M., Beijaard, D., y Ketelaar, E. (2015). Unraveling the complexity of student teachers' learning in and from the workplace. Journal of Teacher Education, 66(4), 334-348. https://doi.org/10.1177/0022487115592163

LePage, P., Darling-Hammond, L., Akar, H., Gutierrez, C., Jenkins-Gunn, E., y Rosebrock, K. (2005). Classroom Management. En Preparing Teachers for a Changing World. What Teachers Should Learn and Be Able to Do (pp. 327-357). Jossey-Bass.

Lipton, B. (2016). La biología de la creencia. La Esfera.

Martínez Bonafé, J. (2010). Aprender el oficio docente sistematizando la práctica. En Á.I. Pérez Gómez (Coord.), Aprender a enseñar desde la práctica: Procesos de innovación y prácticas de formación en la educación secundaria (pp. 107-120). Graó, y Ministerio de Educación. Centro de Publicaciones

Mora, F. (2014). Cómo funciona el cerebro. Alianza Editorial.

Morin, E. (2001). La mente bien ordenada. Seix Barral, S.A.

Motta, J.H. (2017). La actitud de escucha, fundamento de comunicación y la democracia en el aula. Cuadernos de Lingüística Hispánica, 30, 149-169. https://doi.org/10.19053/0121053X.n30.0.6192

Muñoz González, L.C. y Soto Gómez, E. (2020). Mahara como red social y portafolio digital en los nuevos contextos de formación inicial docente. Un estudio de caso. Revista de Educación a Distancia (RED), 20(62), 1-25. https://doi.org/10.6018/red.397021

Muñoz Vita, A. (28 de agosto de 2020). España a la cola de la OCDE en accesibilidad de la educación online. Cinco Días. El País Economía. https://cincodias.elpais.com/cincodias/2020/08/27/fortunas/1598548728_144823 .html

Peña Trapero, N., Serván Núñez, M.J. y Soto Gómez, E. (2016). Creando ambientes de aprendizaje a través de la Lesson Study en la formación inicial de docentes de infantil. En R. I. Herrada, M. T. Cutanda y A. Torres (Eds.), Renovación pedagógica en educación superior (pp. 15-21). Servicio de publicaciones de la Universidad de Murcia. https://libros.um.es/editum/catalog/book/1681

Pérez Gómez, Á. I. (2012). Educarse en la era digital. Morata.

Pérez Gómez, Á. I. (2017). Pedagogías para tiempos de perplejidad. De la información a la sabiduría. Homo Sapiens Ediciones.

Pérez Gómez, Á. I. (2019). Ser docente en tiempos de incertidumbre y perplejidad. Márgenes. Revista de Educación de la Universidad de Málaga, O(0), 3-17. https://doi.org/10.24310/mgnmar.v0i0.6497

Pérez Gómez, A. I. y Soto, E., (2019). La formación del profesorado en tiempos de incertidumbre e individualismo. La relevancia de las Lesson Study. En F.

Reconstruyendo el conocimiento práctico en confinamiento. Una experiencia de enseñanza en la formación inicial de docentes. Soto, Maldonado-Ruiz, Márquez-Román \& Peña. 
Imbernon Muñoz, A. Shigunov Neto, e I. Fortunato (Coords.), Formação permanente de professores: experiências iberoamericanas (pp. 25-51). Ediçoes Hipótese.

Pérez Gómez, Á. I. (2020). Los desafíos educativos en tiempos de pandemias: ayudar a construir la compleja subjetividad compartida de los seres humanos. Praxis educativa, 24(3), 1-24. https://doi.org/10.19137/praxiseducativa-2020-240302

Rosiek, J. y Gleason T. (2017). Philosophy in Research Teacher Education: An Ontoethical Turn. En J. Clandinin y J. Husu (Eds.), The SAGE Handbook of Research on Teacher Education (vol. 2). Sage. http://dx.doi.org/10.4135/9781526402042

Schön, D.A. (1992). La formación de profesionales reflexivos. Hacia un nuevo diseño de la enseñanza y el aprendizaje en las profesiones. Paidós Ibérica.

Schön, D.A. (1998). El profesional reflexivo: cómo piensan los profesionales cuando actúan. Paidós.

Serván, M.J., Soto, E., Peña, N. y Caparrós, R. (24-27 de noviembre, 2017). Lesson Study and Service-Learning in Teacher Preparation [Comunicación en congreso]. World Association of Lesson Study International Conference (WALS), Nagoya (Japón). https://riuma.uma.es/xmlui/handle/10630/17023

Snaza, N., Sonu, D., Truman, S. y Zaliwska, Z. (2016). Pedagogical Matters. New Materialisms and Curriculum Studies. Peter Lang.

Soto, E., Serván, M.J., y Caparrós, R.M. (2011). Escuela y universidad. Crear sentido. Cuadernos de pedagogía, 417, 71-73.

Soto E., Serván, M.J., y Caparrós, R.M. (2016a). Learning to teach with lesson study: The practicum and the degree essay as the scenario for reflective and cooperative creation. International Journal for Lesson and Learning Studies, 5(2), 116-129. https://doi.org/10.1108/IJLLS-12-2015-0042

Soto E. Serván, M.J., y Caparrós, R.M. (2016b). Otra escuela posible: Claves para reconstruir el conocimiento práctico en el contexto universitario. Infancia, 157, 515.

Soto, E., Serván, M.J., Pérez Gómez, A.I. y Peña, N. (2015). Lesson Study and the development of teacher's competences: From practical knowledge to practical thinking. International Journal for Lesson and Learning Studies, 4(3), 209-223. https://doi.org/10.1108/IJLLS-09-2014-0034

Soto, E., y Pérez Gómez, Á.I. (2015). Lessons Studies: un viaje de ida y vuelta recreando el aprendizaje comprensivo. Revista Interuniversitaria de Formación del Profesorado, 29(3), $15-28$. https://dialnet.unirioja.es/servlet/articulo?codigo $=5319583$

Van Manen, M. (1998). El tacto en la enseñanza. El significado de la sensibilidad pedagógica. Paidós Ibérica

Van Manen, M. (2015). Pedagogical Tact. Left Coast Press

Webster-Wright, A. (2009). Reframing professional development through understanding authentic professional learning. Review of Educational Research, 79(2), 702-739. https://doi.org/10.3102/0034654308330970

Reconstruyendo el conocimiento práctico en confinamiento. Una experiencia de enseñanza en la formación inicial de docentes. Soto, Maldonado-Ruiz, Márquez-Román \& Peña. 
Wells G. y Claxton G. (2002). Learning for life in the 21st century: Sociocultural perspectives on the future of education. Blackwell Publishing Ltd.

Zeichner, K. (2010). Nuevas epistemologías en formación del profesorado. Repensando las conexiones entre las asignaturas del campus y las experiencias de prácticas en la formación del profesorado en la universidad. Revista Interuniversitaria de Formación del Profesorado, 68(24), 123-149. http://www.redalyc.org/articulo.oa?id=27419198007. 